\title{
Piezopotential augmented photo- and photoelectro-catalysis with a built-in electric field
}

\author{
Zhirong Liu a,c,, , Xin Yu b,†, Linlin Li a,c,d,* \\ a Beijing Institute of Nanoenergy and Nanosystems, Chinese Academy of Sciences, Beijing 100083, China \\ b Institute for Advanced Interdisciplinary Research (iAIR), University of Jinan, Jinan 250022, Shandong, China \\ c School of Nanoscience and Technology, University of Chinese Academy of Sciences, Beijing 100049, China \\ d Center on Nanoenergy Research, School of Physical Science and Technology, Guangxi University, Nanning 530004, Guangxi, China
}

\section{A R T I C L E I N F O}

\section{Article history:}

Received 27 September 2019

Accepted 10 November 2019

Published 5 April 2020

\section{Keywords:}

Photocatalysis

Photoelectrocatalysis

Piezopotential

Built-in electric field

Piezo-phototronic effect

Reactive oxygen species

\begin{abstract}
A B S T R A C T
Rapid technological development and population growth are responsible for a series of imminent environmental problems and an ineluctable energy crisis. The application of semiconductor nanomaterials in photocatalysis or photoelectrocatalysis (PEC) for either the degradation of contaminants in the environment or the generation of hydrogen as clean fuel is an effective approach to alleviate these problems. However, the efficiency of such processes remains suboptimal for real applications. Reasonable construction of a built-in electric field is considered to efficiently enhance carrier separation and reduce carrier recombination to improve catalytic performance. In the past decade, as a new method to enhance the built-in electric field, the piezoelectric effect from piezoelectric materials has been extensively studied. In this review, we provide an overview of the properties of piezoelectric materials and the mechanisms of piezoelectricity and ferroelectricity for a built-in electric field. Then, piezoelectric and ferroelectric polarization regulated built-in electric fields that mediate catalysis are discussed. Furthermore, the applications of piezoelectric semiconductor materials are also highlighted, including degradation of pollutants, bacteria disinfection, water splitting for $\mathrm{H}_{2}$ generation, and organic synthesis. We conclude by discussing the challenges in the field and the exciting opportunities to further improve piezo-catalytic efficiency.
\end{abstract}

(C) 2020, Dalian Institute of Chemical Physics, Chinese Academy of Sciences. Published by Elsevier B.V. All rights reserved.

\section{Introduction}

With rapid technological development and population growth, environmental problems and an energy crisis are imminent [1,2]. Photocatalysis and photoelectrocatalysis (PEC), with the assistance of rationally designed catalysts, provide green and cost-effective ways to alleviate these problems. They have been developed for the degradation of organic contaminants in the environment, the catalysis of $\mathrm{CO}_{2}$ reduction, $\mathrm{H}_{2}$ evolution and biomass conversion for clean fuels, and catalysis of other reactions [3-7].

Generally, semiconductors with appropriate energies and band gaps can absorb sunlight and form photogenerated electron-hole pairs, which are then transferred to the photocata-

\footnotetext{
* Corresponding author. Tel: +86-10-82854770; Fax: +86-10-82854800; E-mail: lilinlin@binn.cas.cn

$†$ Zhirong Liu and Xin Yu contributed equally to this work.

The work was supported by the Youth Innovation Promotion Association of the Chinese Academy of Sciences (2015023), National Natural Science Foundation of China (81471784, 51802115), Natural Science Foundation of Beijing (2172058), Natural Science Foundation of Shandong Province (ZR2018BEM010, ZR2019YQ21), Major Program of Shandong Province Natural Science Foundation (ZR2018ZC0843), and Scientific and Technology Project of University of Jinan (XKY1923).

DOI: S1872-2067(19)63431-5 | http://www.sciencedirect.com/science/journal/18722067 | Chin. J. Catal., Vol. 41, No. 4, April 2020
} 
lyst's surface, where they trigger oxidative-reductive reactions [8-10]. Unfortunately, limited solar-light utilization and the high recombination rate of the photoinduced electron-hole pairs still hinder their further industrialization [11-13]. In the last few decades, researchers have fabricated many composite photocatalysts to extend the light absorption range from ultraviolet to visible and near infrared regions, such as graphitic carbon nitride $\left(\mathrm{g}-\mathrm{C}_{3} \mathrm{~N}_{4}\right)$ [14,15], $\mathrm{BiVO}_{4}$ [16], $\mathrm{Fe}_{2} \mathrm{O}_{3}$ [17], $\mathrm{Ag}_{3} \mathrm{PO}_{4}$ [18], $\mathrm{WO}_{3}$ [19], CdS [20,21], and $\mathrm{Sn}_{3} \mathrm{O}_{4}$ [22,23]. Furthermore, various modification methods have also been developed to promote the separation of photogenerated electrons and holes, including surface modification [24], metal/nonmetal doping $[25,26]$, and heterojunction construction $[27,28]$. Moreover, the bias voltage can assist in the directional transmission of electrons. Thus, PEC could further enhance carrier separation with the synergy of light illumination and bias voltage [29,30]. However, great challenge still remain for efficient charge separation to improve the performance of photocatalysis and PEC.

Recently, there has been increasing interest in reasonable construction of a built-in electric field by the piezoelectric and piezo-phototronic effects to efficiently enhance carrier separation [31,32]. Piezoelectrics (including ferroelectrics, piezoelectric semiconductors, etc.) are a class of materials with noncentrosymmetric crystal structures [33,34]. Their positive and negative charge centers can be separated under mechanical deformation or an external electric field, which results in the generation of a piezoelectric potential (piezopotential) [35,36]. The piezopotential can modulate the charge carriers at the interface of metal-semiconductor contacts and semiconductor heterojunctions. In the past decade, piezoelectrics have been widely used to regulate the performance of piezoelectric semiconductor devices, such as transistors [37], solar cells [38], light-emitting diodes (LED) [39,40], and self-powered nanosystems [41]. In photocatalysis and PEC, strained piezoelectric semiconductors and ferroelectric materials with permanent polarization show great promise in enhancing carrier separation and reducing carrier recombination via a built-in electric field $[42,43]$.

This review summarizes recent advances in piezocatalysis (including photocatalysis and PEC) enabled and augmented by piezoelectric semiconductors and ferroelectric materials. First, the properties of piezoelectric and ferroelectric materials and the construction mechanism of a built-in electric field for carrier separation are introduced. Second, the methods used to generate a built-in electric field with a piezopotential are discussed, including ultrasonic waves, mechanical brushing/sliding, thermal stress, water flows, and permanent polarization of ferroelectricity. Then, potential applications such as the degradation of pollutants, bacterial disinfection, water splitting for $\mathrm{H}_{2}$ evolution, and organic synthesis are elucidated. Finally, the challenges in the field and the scope for future development of piezo-catalysis are discussed.

\section{Mechanism of piezopotential assisted catalysis}

Fundamentally, the selected polarized material is the key to proper construction of built-in electric fields. It is therefore essential to understand the properties of piezoelectricity and ferroelectricity, and the mechanism through which they cause interface band bending.

\subsection{Piezoelectricity and ferroelectricity}

Piezoelectric materials are a class of dielectric materials with non-centrosymmetric crystal structures, including piezoelectric semiconductors (such as $\mathrm{ZnO}$ [41], $\mathrm{MoS}_{2}$ [44], $\mathrm{MoSe}_{2}$ [45]), all ferroelectric materials (such as $\mathrm{BaTiO}_{3}$ [46], $\mathrm{BiOIO}_{3}$ [47] polyvinylidene fluoride (PVDF) [48], $\mathrm{PbTiO}_{3}$ [49]), and other piezoelectric crystals (such as quartz) (Fig. 1(a)). In this review, we lay emphasis on ferroelectric materials and piezoelectric semiconductors that can enhance catalysis.

Different from ferroelectric materials, piezoelectric materials (green color in Fig. 1(a)) show no polarization without an applied strain (Fig. 1(b)). Taking wurtzite-structured $\mathrm{ZnO}$ as an example [50], the positive $\mathrm{Zn}^{2+}$ and negative $\mathrm{O}^{2-}$ are tetrahedrally coordinated, and in the absence of an external force, the centers of the anions and cations overlap. Thus, there is no piezopotential in the crystal. When the crystal is under a tensile or compressive stress, the $\mathrm{Zn}$ and $\mathrm{O}$ atoms are relatively displaced from their original position. As a result, the centers of the positive and negative charges move to the opposite faces of the tetrahedron crystal, generating a piezopotential. As shown in Fig. 1(b), the tensile and compressive stresses produce a polarized electric field with an opposite direction [51]. Driven by the polarized electric field, photo-generated electrons and holes move towards opposite directions and are separated effectively. As a result, a great number of charge carriers that can take part in redox reactions reach the surface of the catalysts [52].

Different from piezoelectric semiconductors that generate polarized electric field by strain, ferroelectric materials can generate permanent built-in electric fields even without strain (Fig. 1(c)) [53], which is the operational advantage of ferroelectric applications. The applied external electric field or mechanical deformation can induce polarization of the dipole and further adjust the polarized electric field $[31,54]$. However, the insulating properties of traditional ferroelectric materials make them unsuitable for carrier transport. Nanoscaled ferroelectrics do not have this limitation. The lower limit of ferroelectric materials to show ferroelectricity is about a few nanometers [55]. For example, the currently known critical thickness of barium titanate $\left(\mathrm{BaTiO}_{3}\right)$ with ferroelectricity is $2.4 \mathrm{~nm}$ under ambient conditions. However, the thickness of $\mathrm{BaTiO}_{3}$ film for charge tunneling should be lower than $30 \mathrm{~nm}[56,57]$. Therefore, Ba-

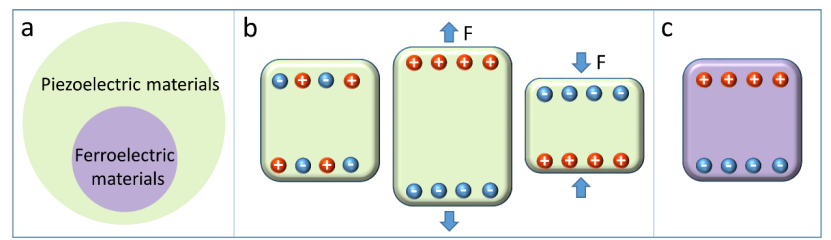

Fig. 1. Piezoelectricity and ferroelectricity. (a) Piezoelectric materials contain ferroelectric materials. (b) Piezoelectric semiconductors in the absence of strain (left), under tensile (middle) and compressive (right) stress. (c) Ferroelectric materials without strain. 
$\mathrm{TiO}_{3}$ with a thickness between $2.4-30 \mathrm{~nm}$ is capable of modulating charges and is suitable for piezocatalysis. For different piezoelectric nanomaterials, the size/thickness window would be different. From another perspective, the surface oxygen defects and foreign ion doping in nanoscaled $\mathrm{BaTiO}_{3}$ could transform it from an insulator into a semiconductor with wide-band gap [58]. Thus, when a ferroelectric material with a suitable thickness is appropriately introduced at the interface of heterojunctions, its electrical modulation capability enables redistribution of the free photogenerated electron-hole pairs, improves the separation efficiency of carriers, and subsequently affects the performance of photocatalysis and PEC.

\subsection{Generation of a built-in electric field}

The photo- and photoelectro-catalytic activity of materials is limited by the recombination of photogenerated electron-hole pairs and the back-reaction of intermediate species [59,60]. A feasible way to enhance photocatalysis is to promote separation and inhibit recombination of the electron-hole pairs. For semiconductor photocatalysts, surface adsorption and foreign atom or surface imperfections (e.g., defects, steps, and impurities) can produce surface states, which are known as extrinsic surface states $[61,62]$. The presence of these surface states would cause charge transfer between the surface of the semiconductor catalyst and the bulk phase, thereby forming a space charge layer [63]. After the charge transfer reaches an equilibrium, the valence band or conduction band of the space charge layer of the semiconductor would bend to form a band bending. The internal electric field generated by ferroelectric polarization, p-n junctions, polar interfaces, and polymorph junctions can change the interface band bending and provide a driving force that promotes the separation of photogenerated carriers [64]. This review focuses on the polarization field built by piezoelectric and ferroelectric materials to promote carrier separation (Fig. 2). Although the built-in electric field could promote carrier separation, it is fixed and easy saturate; therefore, its ability to promote photocatalysis is still limited $[65,66]$. Regenerating the built-in electric field in the photocatalytic process and realizing long-term separation of photogenerated carriers is the key to increasing the performance of the built-in electric

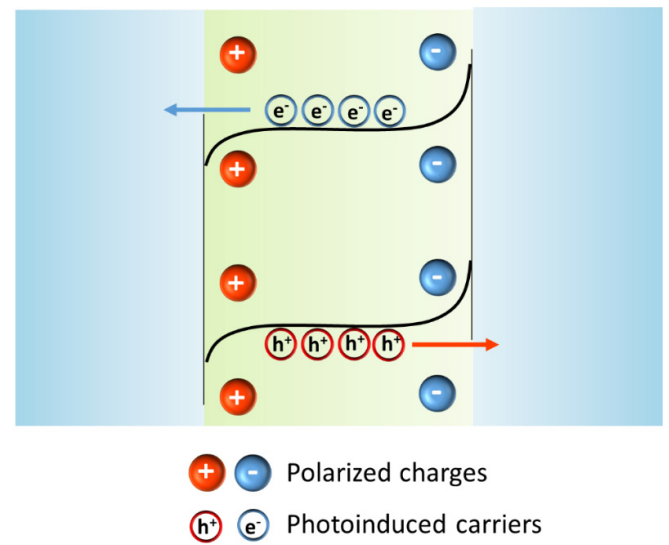

Fig. 2. Scheme of the photogenerated charge carrier separation enhanced by the built-in electric field. field enhanced photocatalysis and realizing photocatalyst recycling.

\section{Built-in electric field mediated catalysis}

As discussed above, a built-in electric field can enhance the separation efficiency of photogenerated electron-hole pairs and subsequently improve the performance of photo- and photoelectro-catalysis. In this section, the specific methods that could be used to construct a built-in electric field with a piezo potential, including ultrasonic irradiation, mechanical brushing/sliding, thermal stress, water flows, and permanent polarization of ferroelectricity are discussed.

\subsection{Piezopotential mediated catalysis}

\subsubsection{Methods used to exert a mechanical stress}

Deformation is an essential requirement for the generation of an internal electric field in piezoelectric semiconductors [67]. To control the strain of piezoelectric semiconductors accurately, Wang's group [68,69] attached a ZnO-based PEC anode to a polymethyl methacrylate (PMMA) cantilever. A speed-controlled motor was employed to drive the dynamic and static bending of the PMMA cantilever (Fig. 3(a)). The distance between the shaft of the motor and the cantilever was adjusted to produce a series of strains. Therefore, the strain on $\mathrm{ZnO}$ could be regulated precisely and calculated by the traditional cantilever model. Xue et al. [70] vertically grew ZnO NWs on carbon fibers (CFs) and bundled several $\mathrm{ZnO} / \mathrm{CFs}$ together. When $\mathrm{ZnO} / \mathrm{CF}$ s were subjected to mechanical brushing/sliding under an external force, ZnO NWs extruded outward and produced a piezopotential across their width (Fig. 3(b)).

An ultrasonic wave is a sound wave with a frequency higher than $20,000 \mathrm{~Hz}$. It has good directionality, strong penetration, and long propagation distance in water. Ultrasound waves are commonly used to generate mechanical forces in piezocatalysis $[71,72]$. Besides the acoustic pressure effect, the ultrasonic cavitation effect is also a major driving force that causes deformation of piezoelectric semiconductors [73]. When the sound pressure reaches a certain value, the tiny bubble nuclei in the liquid expands rapidly and then suddenly close to generate a shock wave. Ultrasonic cavitation includes a series of dynamic processes, such as expansion, closure, and oscillation. Pan et al. [74] first captured the cavitation bubble growth and collapse, and generation of microjets with a high-speed camera (Fig. 3(c) and (d)). Furthermore, the frequency of an ultrasonic wave is high and can easily be adjusted by ultrasonic transducers, which could periodically turn on/off the built-in field to prevent it from being weakened or even degraded by photogenerated carriers [31].

Interestingly, the internal strain induced by thermal stress was employed to modulate compression of $\mathrm{ZnO}$ monocrystalline nanoplatelets [75]. Owing to the mismatched expansion coefficients of $\mathrm{ZnO}$ and $\mathrm{TiO}_{2}$, anisotropic strain was generated in $\mathrm{ZnO} / \mathrm{TiO}_{2}$ hybrid photocatalysts by sintering and cooling (Fig. 3(e)). Different cooling processes (natural cooling in the muffle furnace and rapid cooling in air, ice, and liquid nitrogen) 

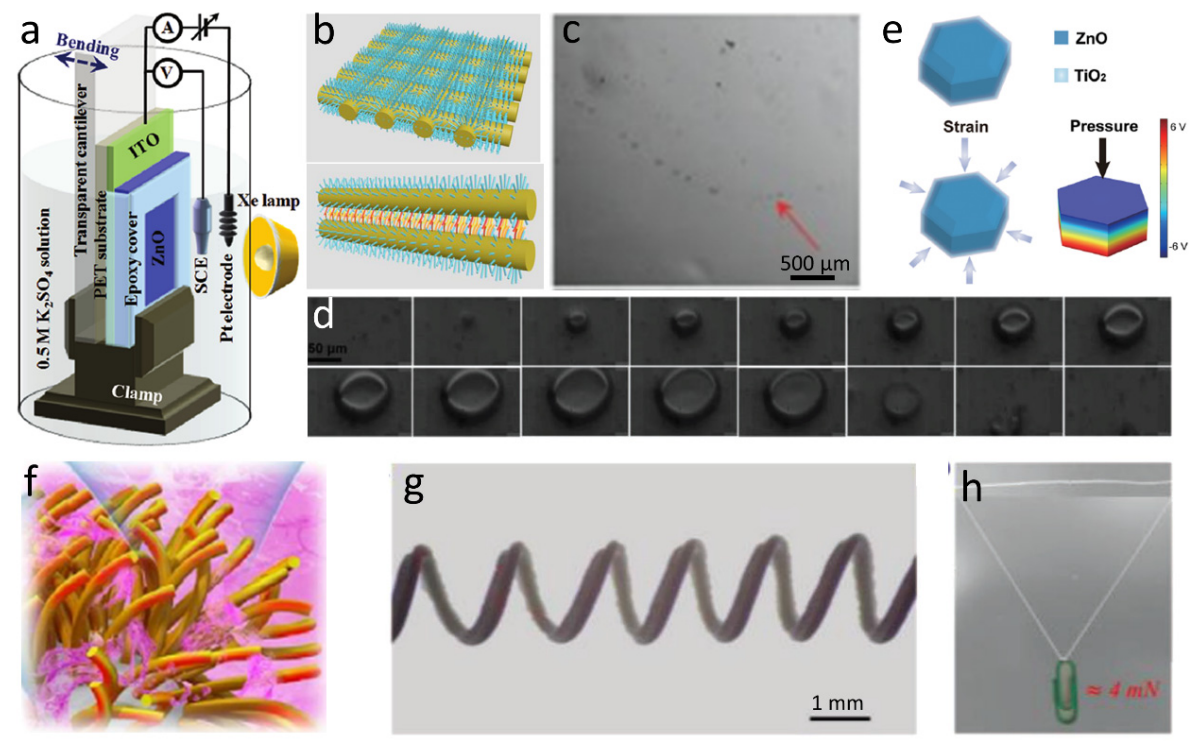

Fig. 3. Methods used to exert a mechanical stress. (a) Schematic setup of the ZnO-based piezoelectric PEC half-cell for precise control of induced strain [68]. Reproduced with permission [68]. Copyright 2011, American Chemical Society. (b) Schematic images of the woven ZnO NWs/CFs and mechanical brushing/sliding under an external force [70]. Reproduced with permission [70]. Copyright 2015, Elsevier. (c) Cavitation clusters consisting of numerous cavitation bubbles in water captured by a high-speed camera. (d) Growth and collapse of cavitation bubbles in the presence of porphyrin-like metal centers (PMCS) and ultrasonic waves [74]. Reproduced with permission [74]. Copyright 2018, Wiley. (e) Schematic demonstration of a $\mathrm{ZnO} / \mathrm{TiO}_{2}$ hybrid without (top) and with strain (bottom left) and it's piezopotential distributions under an axial pressure of 10 MPa (bottom right) [75]. Reproduced with permission [75]. Copyright 2016, American Chemical Society. (f) Schematic image of ZnO nanorod deformation under water flow [76]. Reproduced with permission [76]. Copyright 2017, Elsevier. (g) Optical microphotograph of a PVDF/g-C $\mathrm{N}_{4}$ helical microfiber. (h) Digital photograph of a PVDF/g- $\mathrm{C}_{3} \mathrm{~N}_{4}$ helical microfiber before and after being drawn by a paper clip (about $4 \mathrm{mN}$ ) [52]. Reproduced with permission [52]. Copyright 2019, Wiley.

resulted in different magnitudes of compressive strains along the c-axis direction of $\mathrm{ZnO}$ and further produced different piezoelectric potentials. The $\mathrm{ZnO} / \mathrm{TiO}_{2}$ hybrid photocatalysts cooled at a higher rate had a stronger photocatalytic activity because the residual strain and piezoelectric potential of the sample increased.

There are many ways to induce deformation of piezoelectric semiconductors, but most of them need to be deliberately designed to generate a deformation force, which can control the strain accurately but limit the practical application of the semiconductor. To better utilize the mechanical energy in the natural environment, Chen et al. [76] used water flow to generate stress on $\mathrm{ZnO}$ nanorod arrays vertically grown on a three-dimensional $\mathrm{Ni}$ foam. When water flowed through the $\mathrm{Ni}$ foam, there were some small water turbulences on the inner surface of the foam structure. Meanwhile, the $\mathrm{ZnO}$ nanorods on the Ni foam were also subjected to a mechanical force so that deformation could be generated (Fig. 3(f)). As the stirring rate increased, the deformation of the $\mathrm{ZnO}$ nanorods increased, resulting in a stronger built-in electric field to promote carrier separation. On the other hand, a 3D foam structure was more effective in reactant diffusion and photocharge migration, thereby enhancing photocatalytic activity. In addition, the helical structure was also used to improve deformation in piezoelectric semiconductors [52]. A helical fiber is a typical and intriguing structure in life and nature. Owing to their extraordinary flexibilities, elasticities, and scalabilities, helical microfibers can produce a larger deformation than straight microfibers in simple harmonic vibration systems. By combining a visible-light responsive photocatalyst, g- $\mathrm{C}_{3} \mathrm{~N}_{4}$, with a mainstream organic piezoelectric PVDF, a self-healing internal electric field was constructed for sustainably enhanced photocatalysis (Figs. 3(g) and 3(h)). Reasonable structure design and morphology of a photocatalyst enables it to comprehensively utilize solar energy and mechanical energy in nature, such as wind energy, water flow, tidal energy, etc., which is in line with sustainable development strategies [77].

\subsubsection{Catalysts with piezoelectric effects}

The most widely used method for constructing a piezoelectric catalytic system is using the piezopotential of piezoelectric semiconductors to separate photo-induced carriers generated by photocatalysts [78]. For example, various semiconductor photocatalysts $\left(\mathrm{TiO}_{2}, \mathrm{BiOI}\right.$, and $\left.\mathrm{CdS}\right)$ were hybridized on a soft porous piezoelectric polymeric film rGO-F/PVDF-HFP (4-azidotetrafluorobenzoic acid-modified graphene/polyvinylidene fluoride-co-hexafluoropropylene) (Fig. 4(a)) [79]. $\mathrm{TiO}_{2}, \mathrm{BiOI}$, and $\mathrm{CdS}$ are representative of classical UV-active catalysts, visible-light-active photocatalysts, and $\mathrm{H}_{2}$ evolution catalysts, respectively, which can generate electron-hole pairs under light illumination in a specific wavelength range. Furthermore, a rGO-F/PVDF-HFP piezoelectric film can harvest gentle mechanical disturbances in typical catalytic settings to form a piezoelectric field. This electric field enhanced photocatalytic performances of $\mathrm{TiO}_{2}$, BiOI, and CdS by $300 \%$, 21\%, and 400\%, respectively (Fig. 4(b)-(d)). Dai et al. [52] combined visible-light responsive g- $\mathrm{C}_{3} \mathrm{~N}_{4}$ with a helical organic piezoelectric PVDF to construct a self-healing internal electric 

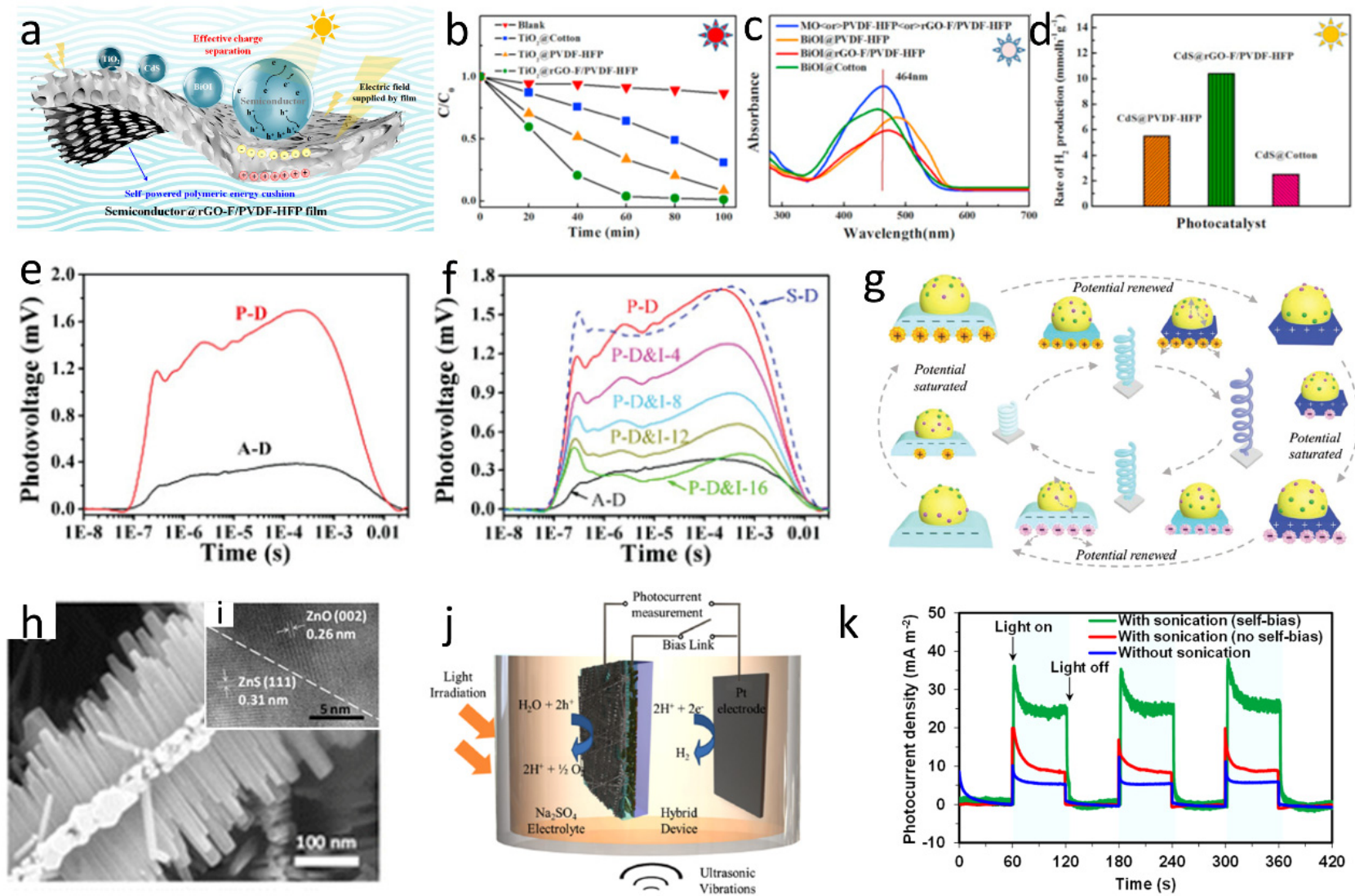

Fig. 4. Catalysts with a piezoelectric effect. (a) Schematic illustration of the design concept of the hybrid piezophotocatalyst. The process includes the mounting of semiconductor catalysts onto a self-powered energy cushion, which was a composite film of rGO-F/PVDF-HFP. (b) Photocatalytic degradation of MO catalyzed by $\mathrm{TiO}_{2} @ \mathrm{rGO}-\mathrm{F} / \mathrm{PVDF}-\mathrm{HFP}$ under UV light. (c) Absorbance of MO catalyzed by BiOI@rGO-F/PVDF-HFP after 24 h under ambient light. (d) Photocatalytic $\mathrm{H}_{2}$ evolution rate of CdS@rGO-F/PVDF-HFP under visible light [79]. Reproduced with permission [79]. Copyright 2018, Elsevier. (e) Transient photovoltages of PVDF/g- $\mathrm{C}_{3} \mathrm{~N}_{4}$ composite films on a logarithmic timescale under $355 \mathrm{~nm}$ pulse laser irradiation in the absence (A-D) and presence (P-D) of film deformation, respectively. (f) Variation in the transient photovoltages of the PVDF/g- $\mathrm{C}_{3} \mathrm{~N}_{4}$ film with plus laser illumination and deformation. P-D\&I-4, P-D\&I-8, P-D\&I-12, and P-D\&I-16 stand for the transient photovoltages detected in the presence of film deformation and pulse laser irradiation for 4, 8, 12, and $16 \mathrm{~min}$, respectively. S-D presents the transient photovoltage characterized after the film was deformed again. (g) Diagram showing the process by which the piezoelectric potential in a PVDF/g-C ${ }_{3} \mathrm{~N}_{4}$ composite helical microfiber is saturated and self-renewed, and the corresponding carrier transfer behavior [52]. Reproduced with permission [52]. Copyright 2019, Wiley. (h) Scanning electron microscope (SEM) image of AZ. (i) High resolution transmission electron microscope (HRTEM) image of ASZS. (j) Schematic illustration of a self-bias hybrid system via a bias link with the corresponding enhanced (k) photocurrent measurement [80]. Reproduced with permission [80]. Copyright 2015, American Chemical Society.

field for sustainably enhanced photocatalysis. The photovoltage of PVDF/g- $\mathrm{C}_{3} \mathrm{~N}_{4}$ after deformation was $1.7 \mathrm{mV}$, fourfold higher than that before the film was deformed (Fig. 4(e)), which implied that the deformation of the PVDF/g- $\mathrm{C}_{3} \mathrm{~N}_{4}$ film was conducive to the separation and propagation of photogenerated carriers. The photocatalytic performance was enhanced significantly when microfibers experienced simple harmonic vibration. Importantly, the piezoelectric field caused by deformation could be saturated within about 10 min under persistent pulse laser irradiation (Fig. 4(f)) and refreshed after the film was deformed again. Therefore, periodic deformation or a self-healing structure is important for continuous generation of built-in electric fields in piezoelectric semiconductors. When a strain was applied on the PVDF fiber, the resulting piezopotential bent the energy band of $\mathrm{C}_{3} \mathrm{~N}_{4}$, and then the generated built-in electric field promoted the separation of photoinduced electron and hole pairs. However, this electric field could be easily saturated by photoinduced carries and outer charged ions, halting the enhancement of photocatalysis. To overcome this problem, in this self-healing piezoelectric catalytic system, an opposite potential was generated via deformation again to repel nearby holes and attract electrons (Fig. 4(g)). The self-healing behavior could sustainably inhibit the recombination of photogenerated carriers and significantly enhance the piezocatalytic effect.

Tan et al. [80] constructed a self-biased hybrid piezoelectric-photoelectrochemical cell with photocatalytic functionalities. ZnO nanorods (NRs) were grown on $\mathrm{Ag}$ or $\mathrm{Cu}$ nanowires (NWs) via a galvanic displacement deposition method (Fig. 4(h)). Then, Ag-ZnO (AZ) and $\mathrm{Cu}-\mathrm{ZnO}$ (CZ) were sulfurized to form a core-shell structure $\mathrm{Ag} / \mathrm{Ag}_{2} \mathrm{~S}-\mathrm{ZnO} / \mathrm{ZnS}$ (ASZS) and $\mathrm{Cu} / \mathrm{CuS}-\mathrm{ZnO} / \mathrm{ZnS}$ (CSZS). The lattice spacing of the core and shell was 0.26 and $0.31 \mathrm{~nm}$, matching well with the (002) of $\mathrm{ZnO}$ and (111) planes of ZnS, respectively (Fig. 4(i)). By hybridizing the wide bandgap materials ( $\mathrm{ZnO}$ and $\mathrm{ZnS}$ ) with the narrow bandgap materials $\left(\mathrm{Ag}_{2} \mathrm{~S}\right.$ or $\left.\mathrm{CuS}\right)$, a composite with a 
low bandgap and increased sensitivity to visible light was fabricated. Owing to the piezoelectricity of $\mathrm{ZnO}$, a piezoelectric charge would be generated in the hybrid battery under an ultrasonic wave, and the charge transfer occurred between the Ag NWs electrode and the Pt counter electrode of the PEC battery. This created a voltage bias that improved the photocurrent density from 8 to $22 \mathrm{~mA} \mathrm{~m}^{-2}$. When the Ag NWs electrode of the hybrid battery was disconnected from the Pt counter electrode (Fig. 4(j)), the photocurrent decreased (Fig. 4(k)), indicating that the self-bias from the piezopotential had a significant effect on the photocurrent. This could pave the way for a new generation of self-powered photocatalytic devices for solving environmental and energy crises.

\subsubsection{Catalysts with a piezophototronic effect}

Wang and co-workers [41] first proposed the concept of the piezophototronic effect in 2010. Piezoelectric semiconductors, such as wurtzite structure $\mathrm{ZnO}, \mathrm{GaN}, \mathrm{InN}$, and CdS [81], have coupling properties of piezoelectricity, semiconductor charge transport, and light excitation, providing a new fundamental piezo-photocatalytic mechanism to modulate the separation of photogenerated carriers. The piezoelectric optoelectronic effect utilizes the piezopotential to regulate the generation, separation, transport, and recombination processes of interface or junction carriers (Fig. 5), which drive the development of high-performance optoelectronic devices [82]. Wurtzite zinc oxide $(\mathrm{ZnO})$ is a representative piezoelectric semiconductors. The bandgap of $\mathrm{ZnO}$ is $\sim 3.37 \mathrm{eV}$, which is favorable for generating electron-hole pairs under UV light irradiation. In addition, it has high piezoelectric coefficients $\left(10-30 \mathrm{pm} \mathrm{V}^{-1}\right.$ for $\mathrm{d}_{33}$ and about $5 \mathrm{pm} \mathrm{V}^{-1}$ for $\mathrm{d}_{31}$ ) [83]. Through the simple seed-assisted hydrothermal method, single crystal ZnO NWs can grow on substrates of different materials and shapes [70,76], providing significant cost and process advantages for potential industrial applications.

Xue et al. [70] synthesized ZnO NWs on carbon fibers (CFs) (Fig. 6(a)) and co-used photonic and mechanical energy for the degradation of organic dyes by coupling the piezoelectric and photocatalytic properties of ZnO NWs. The piezoelectric effect of $\mathrm{ZnO} \mathrm{NWs} / \mathrm{CFs}$ was measured based on the mechanism of a fiber nanogenerator. When the experimental vibration distance was about $1 \mathrm{~cm}$, the open-circuit voltage and short-circuit current were about $20 \mathrm{mV}$ and $0.5 \mathrm{nA}$, respectively. When $\mathrm{ZnO}$

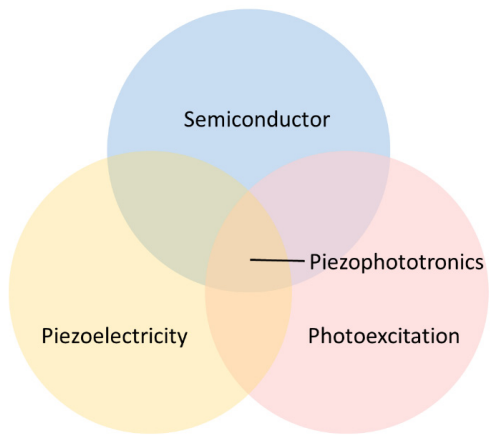

Fig. 5. Scheme of the piezophototronic effect. Coupling among piezoelectric, optical, and semiconducting properties in piezoelectric semiconductor materials is the basis of piezo-phototronics.
NWs were exposed to UV light, photogenerated electron-hole pairs were generated. At the same time, a periodic force was applied to $\mathrm{ZnO} \mathrm{NWs} / \mathrm{CFs}$, causing relative sliding between adjacent ZnO NWs and bending of the NWs. Therefore, a piezoelectric field was formed across their widths, which drove the migration of photo-generated electrons to the positive potential side (stretching side) and holes to the negative potential side (compressed side) (Fig. 6(b)). It increased the separation efficiency of photogenerated electron and holes. More carriers could migrate to the surface, form free radicals, and degrade methylene blue (MB) in an aqueous solution. Moreover, the photodegradation profiles of the MB solution catalyzed by $\mathrm{ZnO}$ NWs/CFs increased with increasing frequency of the applied force from 0 to $1 \mathrm{~Hz}$ owing to a higher input power (Fig. 6(c)). Similarly, a nanocomposite with $\mathrm{ZnO}$ nanorod arrays grown vertically on the 3D Ni foam was synthesized to photocatalytically degrade rhodamine $\mathrm{B}(\mathrm{RhB})$ [76]. The photocurrent at a stirring rate of $500 \mathrm{rpm}$ was higher than that obtained under static condition $(0 \mathrm{rpm})$. As the stirring rate was increased to $1000 \mathrm{rpm}$, the photocurrent density also further increased. This was because the water flow velocity increased as the stirring rate increased. Therefore, the $\mathrm{ZnO}$ nanorods on the surface of the Ni foam experienced an enhanced deformation degree, inducing an enhanced piezoelectric field. The increased piezoelectric field can promote the separation of photogenerated electron and holes. Therefore, the $\mathrm{ZnO}$ nanorod arrays/Ni foam showed an increasing photocurrent as the stirring rate increased. Mushtaq et al. [84] fabricated single-crystalline $\mathrm{BiFeO}_{3}$ NWs (BFO NWs, Fig. 6(d)) that can successfully utilize visible light and mechanical vibrations to degrade organic pollutants. Fig. 6(e) shows that BFO NWs exhibited strong absorption in the UV and visible regions, and the bandgap of BFO NWs was $2.1 \mathrm{eV}$. The piezoelectricity of a single BFO NW was directly probed using a piezoresponse force microscopy (PFM). From the PFM phase images (Fig. 6(f)), a clear phase contrast between different regions of the NW could be observed, which represented the domains with opposite out-of-plane polarization orientations. The amplitude image shows the presence of distinct and randomly distributed ferroelectric domains. From the phase loop presented, it could be clearly observed that the polarization can be switched to the opposite direction by sweeping the tip bias, and the average phase contrast is close to $180^{\circ}$. The amplitude of the response signal in PFM was directly related to the local strain of the BFO nanostructures. This amplitude versus bias voltage curve was also hysteretic, and its shape resembled a butterfly loop. These results confirmed the ferroelectric nature of BFO NW. When sunlight and an ultrasound wave were used simultaneously, $97 \%$ of the RhB dye was degraded within $1 \mathrm{~h}$.

The piezoelectric semiconductor $\mathrm{ZnO}$ was also used to tune PEC water splitting. The PEC anode was a ZnO thin film deposited on the ITO electrode [68]. The prepared $\mathrm{ZnO}$ thin film had a resistivity of about $10^{7} \Omega \cdot \mathrm{cm}$, which had reasonable charge conductance for water oxidation under illumination and could generate a high piezopotential when deformed. Under a $1.5 \mathrm{~V}$ bias and $100 \mathrm{~mW} \mathrm{~cm}^{-2}$ light intensity, the photocurrent density $(\mathrm{ph})$ increased by $10.2 \%$ or decreased by $8.5 \%$ when the $\mathrm{ZnO}$ 

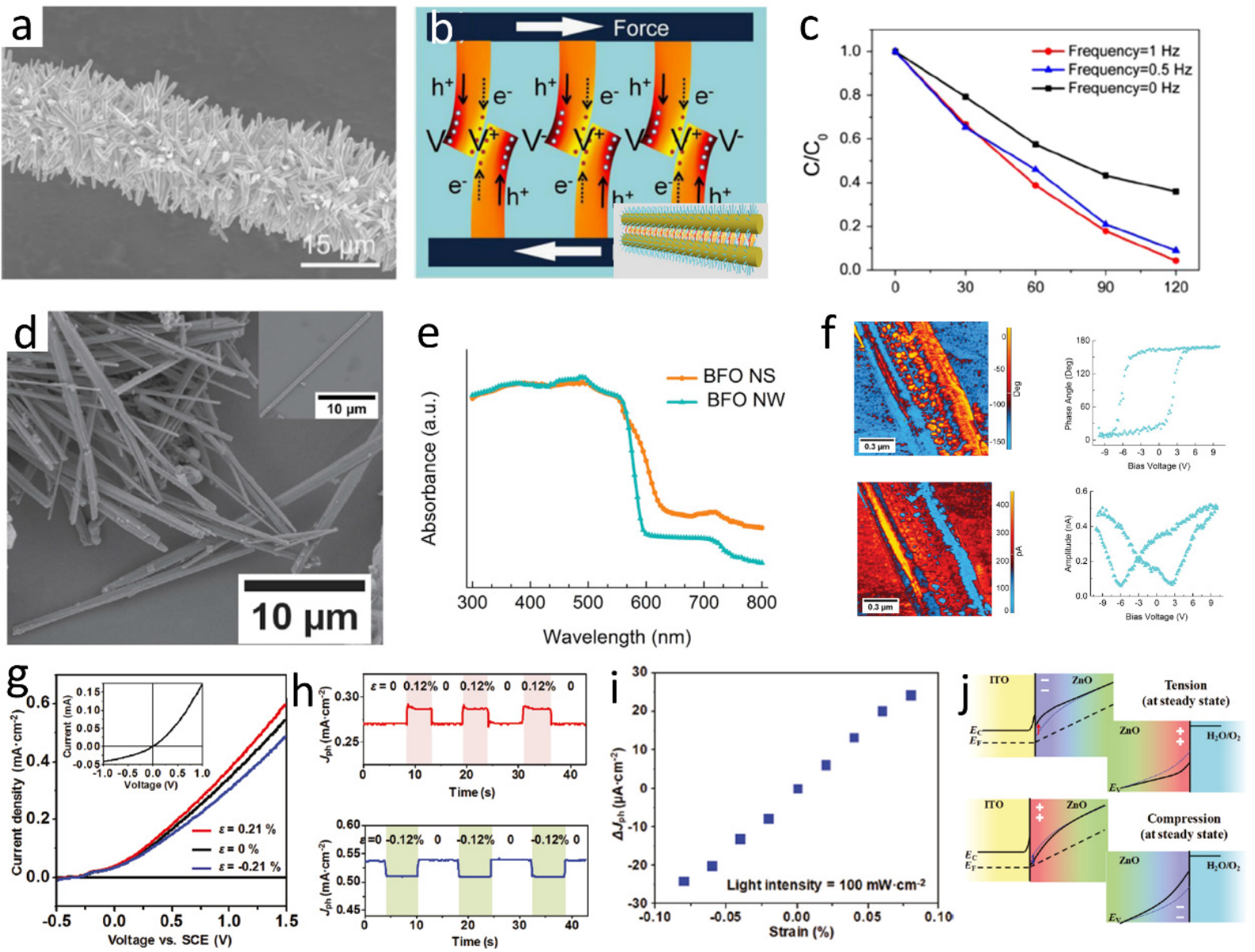

Fig. 6. Catalysts with a piezophototronic effect. (a) SEM image of ZnO NWs/CFs. (b) When a periodic force was applied on ZnO NWs/CFs, there was a relative sliding between neighboring $\mathrm{ZnO} \mathrm{NWs}$, resulting in the bending of $\mathrm{ZnO} \mathrm{NWs}$, which produced positive and negative piezoelectric potentials across their widths. Furthermore, the piezoelectric field could drive the electrons and holes to migrate to the surface in opposite directions. The recombination of electrons and holes could be reduced. (c) Photodegradation curves of an MB solution catalyzed by ZnO NWs/CFs. Forces with different frequencies were applied. "Frequency $=0$ " represents a non-piezo-assisted photocatalytic process [70]. Reproduced with permission [70]. Copyright 2015, Elsevier. (d) SEM image showing several BFO NWs. In the inset, a single NW is shown. (e) UV-Vis diffuse reflectance spectrum spectra obtained for BFO nanosheets (NS) and NW samples. (f) PFM characterization of BFO NW showing the phase response (top) and amplitude response (bottom) [84]. Reproduced with permission [84]. Copyright 2018, Elsevier. (g) $J$ - $V$ curves and dark current density of the ZnO PEC cell with and without strain applied to the $\mathrm{ZnO}$ thin film. Inset is the I-V curve of an as-synthesized ITO-ZnO heterojunction, showing a diode-like performance. (h) Photo current density $(\mathrm{ph})$ of the $\mathrm{ZnO}$ PZ-PEC under periodic strains $\left(0.12 \%\right.$ under illumination of $50 \mathrm{~mW} \mathrm{~cm}^{-2}$ and $-0.12 \%$ under illumination of 100 $\mathrm{mW} \mathrm{cm}-2$ ) at an applied bias of $1.5 \mathrm{~V}$ versus that of a saturated calomel electrode (SCE). The strained regions are marked with a shade of light green or red. (i) Photocurrent density change $\left(\Delta \mathrm{J}_{\mathrm{ph}}\right)$ as a function of applied strain under an illumination of $100 \mathrm{~mW} \mathrm{~cm}^{-2}$. The back ground $J_{\mathrm{ph}}$ was $540 \mu \mathrm{A} \mathrm{cm}{ }^{-2}$ and applied bias was $1.5 \mathrm{~V}$ versus that of an SCE. (j) Schematic electronic band diagram of the ITO/ZnO interface under tension and compression [68]. Reproduced with permission [68]. Copyright 2011, American Chemical Society.

anode was stretched or compressed by $0.21 \%$, respectively (Fig. 6(g)). There was a similar variation in Jph when a constant strain was applied to the ZnO anode periodically (Fig. 6(h)). Moreover, the relationship between the relative photocurrent change and strain was approximately linear (Fig. 6(i)). The photocurrent change was due to the remnant piezoelectric potential across the interface of ZnO/ITO under strain, which resulted in a slight variation in barrier height. This effect was different from the flow of carriers driven by piezopotential, although it was also caused by the piezoelectric effect (Fig. 6j). In this system, the change in barrier height was low $(\sim 1.5 \mathrm{mV}$ at a $0.1 \%$ strain), but the resulting photocurrent change was significant (5.6\%) owing to the exponential relationship between the current and the barrier height. This discovery provides a new approach for designing interface barriers, which are beneficial for improving the efficiency of many electronics, optoelectronics, and photovoltaic devices.

\subsection{Ferroelectric polarization mediated catalysis}

Ferroelectric materials can form spontaneous dipole moments without the need of an additional mechanical force, which can generate a polarization electric field that drives the transfer and separation of photogenerated carriers and thus improves photocatalytic efficiency [85,86]. Cheng et al. [53] selectively spatial-constructed an $\mathrm{Au}$ nanolayer and $\mathrm{SrTiO}_{3}$ nanocubes on the inner and outer surfaces of $\mathrm{TiO}_{2}$ nanotubes to accelerate carrier separation and improve PEC performance. The $\mathrm{SrTiO}_{3}$ nanocubes with spontaneous ferroelectric polarization could effectively engineer the band bending of $\mathrm{TiO}_{2}$, which 
was beneficial to the transfer of holes to the electrode/electrolyte interface for water oxidation. The photocurrent density of $\mathrm{SrTiO}_{3} / \mathrm{TiO}_{2} / \mathrm{Au}$ photoanode at $1.23 \mathrm{~V}$ (vs. RHE) was enhanced significantly, as it was about 3.5 times higher than that of the pristine $\mathrm{TiO}_{2}$ nanotube arrays.

Although ferroelectric materials could form spontaneous polarization electric fields, the magnitude of the strength of the electric field is often limited by the nature of the material. Huang et al. [47] proposed an ionic substitution strategy by replacing $\mathrm{I}^{5+}$ with $\mathrm{V}^{5+}$ to increase the dipole moment of a $\mathrm{IO}_{3}$ polyhedron (Fig. 7(a)). According to theoretical calculations, the polyhedral distortion of $\mathrm{IO}_{3}$ in $\mathrm{BiOI}_{0.926} \mathrm{~V}_{0.074} \mathrm{O}_{3}(0.065)$ was greater than that in $\mathrm{BiOIO}_{3}(0.063)$, indicating that $\mathrm{V}$ replacement caused a substantial increase in the macroscopic polarization of $\mathrm{BiOIO}_{3}$. The enhanced polarization electric fields sig- nificantly promoted the separation of carriers, which facilitated molecular oxygen activation for producing superoxide radicals $\left(\bullet \mathrm{O}_{2}{ }^{-}\right)$and hydroxyl radicals $(\bullet \mathrm{OH})$ in piezocatalytic processes (Figs. 7(b) and 7(c)).

The applied external electric field can also induce polarization of the dipoles and further enhance the polarized electric field. Wen et al. [87] found that polarization treatment changed the unit cell parameters of the crystal and caused the unit cell to distort. Our group has constructed a multilayered coaxial titanium dioxide/ barium titanate/ silver oxide $\left(\mathrm{TiO}_{2} / \mathrm{BTO} / \mathrm{Ag}_{2} \mathrm{O}\right)$ coaxial nanorod array as the photoanode for PEC water splitting (Fig. 7(d)) [54]. The thickness of the $\mathrm{BaTiO}_{3}$ was $6-8 \mathrm{~nm}$, above the currently known critical thickness $(\approx$ $2.4 \mathrm{~nm}$ ) of $\mathrm{BaTiO}_{3}$ with ferroelectricity under ambient conditions. The $\mathrm{TiO}_{2} / \mathrm{BTO}$ interface showed a good crystalline lattice
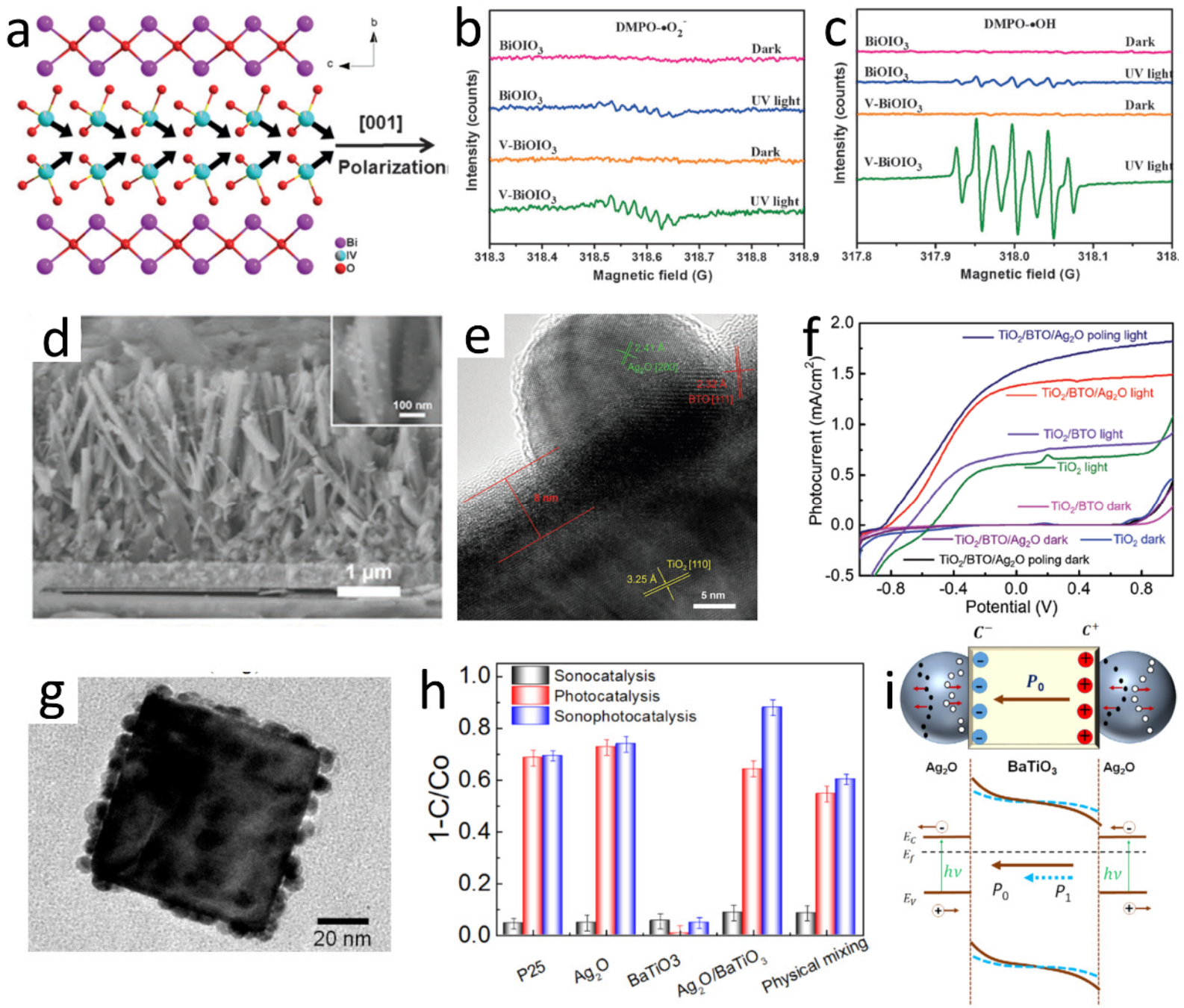

Fig. 7. Ferroelectric polarization mediated catalysis. (a) Crystal structure of $\mathrm{V}-\mathrm{BiOIO}_{3}\left(\mathrm{BiOI}_{0.926} \mathrm{~V}_{0.074} \mathrm{O}_{3}\right)$ along b-c planes (Black arrows indicate polar-

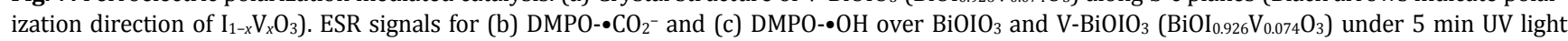
illumination [47]. Reproduced with permission [47]. Copyright 2017, Wiley. (d) Cross-sectional view of TiO $2 / \mathrm{BTO} / \mathrm{Ag}_{2} \mathrm{O}$ nanorod. (e) $\mathrm{HRTEM}$ image of $\mathrm{TiO}_{2} / \mathrm{BTO} / \mathrm{Ag}_{2} \mathrm{O}$ nanorod. (f) Current-voltage (J-V) curve in the dark and under Xe lamp irradiation of the different photoanodes [54]. Reproduced with permission [54]. Copyright 2019, Wiley. (g) TEM image of $\mathrm{Ag}_{2} \mathrm{O}-\mathrm{BaTiO}_{3}$ nanocube. (h) Sonocatalytic, photocatalytic, and sonophotocatalytic degradation of $\mathrm{RhB}$ in the presence of $\mathrm{P} 25, \mathrm{Ag}_{2} \mathrm{O}$ nanoparticles, $\mathrm{BaTiO}_{3}$ nanocubes, $\mathrm{Ag}_{2} \mathrm{O}-\mathrm{BaTiO}_{3}$ hybrid nanocubes, and physically mixed $\mathrm{BaTiO}-\mathrm{Ag}_{2} \mathrm{O}$ powder for $1 \mathrm{~h}$. (i) The separation of electrons and holes in $\mathrm{Ag}_{2} \mathrm{O}$ nanoparticles attached to the two opposite surfaces of a $\mathrm{BaTiO}_{3}$ nanocube that had opposite polarization charges owing to the piezoelectric effect and the corresponding tilting in the bands. The solid line represents the bands with the presence of spontaneous polarization charges at the two surfaces of the $\mathrm{BaTiO}_{3}$ nanocube; the dashed line indicates a decrease in the piezoelectric polarization with a mechanical strain [31]. Reproduced with permission [31]. Copyright 2015, American Chemical Society. 
match, indicating that the interface has high coherence (Fig. $7(\mathrm{e})$ ). The insertion of a ferroelectric $\mathrm{BaTiO}_{3}$ nanolayer between the n-type semiconductor $\mathrm{TiO}_{2}$ and p-type semiconductor $\mathrm{Ag}_{2} \mathrm{O}$ created a stabilized polarized electrical field. After $\mathrm{TiO}_{2} / \mathrm{BTO} / \mathrm{Ag}_{2} \mathrm{O}$ nanorod arrays were poled with a $+2 \mathrm{~V}$ voltage for $1 \mathrm{~min}$, the photocurrent density of the $\mathrm{TiO}_{2} / \mathrm{BTO} / \mathrm{Ag}_{2} \mathrm{O}$ poling in the full-spectrum simulated sunlight was $1.8 \mathrm{~mA} \mathrm{~cm}^{-2}$ at the bias of $0.8 \mathrm{~V}$, which was about 1.2 times that of $\mathrm{TiO}_{2} / \mathrm{BTO} / \mathrm{Ag}_{2} \mathrm{O}$ without poling (Fig. 7(f)). This positive polarization enhanced the built-in electric field, which sustainably attracted the electrons of $\mathrm{Ag}_{2} \mathrm{O}$ on one end and rejected the electrons of $\mathrm{TiO}_{2}$ on other end, thereby inhibiting recombination of the photogenerated carriers.

Besides the ionic substitution strategy and applied external electric field, the original dipole polarization of ferroelectric crystal can also be altered by mechanical deformation owing to piezoelectricity. If an external mechanical force with an appropriate direction was applied to the piezoelectric semiconductors, the polarized electric field could be further enhanced. However, an opposite direction force would reduce the intensity of the polarized electric field and even reverse the direction of the original polarization. Li et al. [31] enhanced ferroelectric-nanocrystal-based hybrid photocatalysis by an ultrasonic-wave-generated piezoelectric effect. Ferroelectric $\mathrm{BaTiO}_{3}$ nanocubes and the visible light responsive photocatalyst $\mathrm{Ag}_{2} \mathrm{O}$ were combined to form an $\mathrm{Ag}_{2} \mathrm{O}-\mathrm{BaTiO}_{3}$ hybrid photocatalyst (Fig. 7(g)). The spontaneous polarization potential of $\mathrm{BaTiO}_{3}$ nanocubes can be used to construct a built-in electric field, and an ultrasonic wave was applied to further regulate the polarization potential. On one hand, ultrasonic wave-induced deformation of $\mathrm{BaTiO}_{3}$ could enhance the original polarization and promote directional migration and separation of photogenerated carriers. On the other hand, the periodic pressure generated by an ultrasonic wave could alternately alter the polarization potential, which can prevent the saturation of the static built-in field created by the ferroelectric effect. Therefore, the built-in electric field induced by the periodically attractive and repulsive process of the carriers under ultrasonic irradiation could continuously enhance the photocatalytic activity of an $\mathrm{Ag}_{2} \mathrm{O}-\mathrm{BaTiO}_{3}$ hybrid photocatalyst through an enhancement of photoinduced carrier separation (Figs. 7(h) and 7(i)).

\section{Applications}

The built-in electric field formed by the piezopotential can significantly improve catalytic efficiency, which can further promote the application of photo- and photoelectro-catalysis. In this section, we will present the potential applications of piezocatalysis, such as degradation of pollutants (Section 4.1), bacterial disinfection (Section 4.2), water splitting for $\mathrm{H}_{2}$ evolution (Section 4.3), and organic synthesis (Section 4.4). Several representative examples based on different application areas have been described.

\subsection{Degradation of pollutants}

With the rapid development of industrialization, a wide range of harmful and toxic organic pollutants are continuously discharged into the environment $[21,88]$. Natural biodegradation cannot effectively decompose these substances, which not only causes concerns for ecosystems, but also threatens human health and life [89]. In order to achieve the goals of environment protection and sustainable development, photocatalytic degradation of pollutants is an important strategy with wide interest in the scientific community. It can completely degrade the organic pollutants into harmless inorganic substances (such as $\mathrm{CO}_{2}, \mathrm{H}_{2} \mathrm{O}$, etc.) in a relatively mild condition [90-92]. However, the limited catalytic effect caused by the high electron-hole recombination rate restricts its industrial development. Reasonable construction of built-in electric fields by the piezoelectric effect or ferroelectric polarization can efficiently enhance the photoinduced carrier separation $[67,76,93]$. Then, highly active electrons and holes undergo redox reactions on the surface of the photocatalysts. The photogenerated electrons react with surface-adsorbed molecular $\mathrm{O}_{2}$ to form the superoxide anion radical $\bullet \mathrm{O}_{2}$ - At the same time, the photogenerated holes react with surface $\mathrm{OH}^{-}$from water to produce $\bullet \mathrm{OH}$ radicals. The reaction of $\bullet \mathrm{O}_{2}{ }^{-}$and $\bullet \mathrm{OH}$ radicals with organic pollutants would ultimately lead to the mineralization of these compounds [94-96]. The most widely used pollutant model molecules for the evaluation of photocatalytic degradation are liquid phase methyl orange, $\mathrm{MB}, \mathrm{RhB}$, and phenol, as well as gas phase formaldehyde, acetaldehyde, and NO. Zhang et al. [97] securely immobilized a piezoelectric semiconductor $\mathrm{ZnO}$ nanowire array on a floatable photocatalytic platform for high-performance water decontamination. In the presence of an ultrasonic field, the degradation rate of methylene blue was $20 \%$ higher than that under only UV light irradiation. This was because the piezoelectric potential generated by $\mathrm{ZnO}$ during ultrasonic bending could promote the separation of photogenerated electrons and holes. As the number of charge carriers increased, more reactive oxidants were converted, ultimately improving the degradation capacity. Crude oil was used as another target pollutant to assess the photodegradation capability of piezocatalysts. The promising degradation of crude oil reveals the potential application of the platform in gasoline pollution treatment. CuS/ZnO NWs as a piezo-photocatalyst was also employed to degrade organic dyes using both solar and mechanical energy [98]. Owing to the built-in electric field created by ZnO NWs under ultrasonic irradiation, the photocatalytic activity of $\mathrm{CuS} / \mathrm{ZnO}$ increased by about 3 times, and almost all the MB was degraded within 20 min under both solar and ultrasonic irradiation. Liu et al. [99] synthesized $\mathrm{BiFeO}_{3} / \mathrm{TiO}_{2}$ core-shell nanocomposites for the degradation of an organic dye molecule through a combination effect of the piezo- and photo-catalytic activities. By utilizing the hybrid catalyst, the reaction constant of $\mathrm{BiFeO}_{3} / \mathrm{TiO}_{2}$ for dye degradation was $566 \%$ and $388 \%$ higher than those of the sole piezocatalytic and photocatalytic processes, respectively. Therefore, the synergy of piezo- and photo-catalysis paves the way for constructing efficient catalytic systems for environmental management.

\subsection{Bacteria disinfection}


In recent years, bacteria have evolved and become resistant to our frontline drugs owing to the abuse of antibiotics and fungicides [100-102]. These super-bacteria pose a serious threat to the ecological environment and human health, demonstrating the need for more effective sterilization technologies [103,104]. In 1985, Matsunaga et al. [105] first reported that microbial cells in water could be killed by a $\mathrm{TiO}_{2}$ photocatalyst under UV light irradiation, which created a new avenue for disinfection and sterilization in public health care and ecosystem. The photocatalytic antibacterial agents are long-lasting, robust to drug resistance development, ensure complete sterilization, etc. They are also non-toxic, tasteless, and not irritative to the skin [106,107]. Under light irradiation, photocatalysts produce photoinduced reactive oxygen species (ROS), including peroxide $\left(\mathrm{H}_{2} \mathrm{O}_{2}\right)$, superoxide $\left(\mathrm{O}_{2} \bullet^{-}\right)$, hydroxyl radicals $(\bullet \mathrm{OH})$, and singlet oxygen $\left({ }^{1} \mathrm{O}_{2}\right)[108,109]$, which cause peroxidation of the polyunsaturated phospholipid in the bacterial lipid membrane and therefore disruption of cellular respiration, thereby killing the bacteria [110]. Therefore, efficient production of ROS is the key to the photocatalytic sterilization process. By introducing a piezoelectric material into the photocatalytic system and constructing a reasonable built-in electric field, the photoinduced electrons and holes could be effec- tively separated, further reacting to generate more ROS for sterilization. The piezoelectric properties of $\mathrm{MoS}_{2}$ have been proposed and used in piezocatalysis under light irradiation or dark conditions [111-114]. Wang et al. [44] reported that the periodic stretching and releasing of odd layered $\mathrm{MoS}_{2}$ flakes to produce piezoelectric voltage and current outputs, because of the lattice distortion induced by deformation and the concomitant ion charge polarization. However, this piezoelectric effect disappeared in even layered or bulk $\mathrm{MoS}_{2}$ owing to the opposite orientations of adjacent atomic layers $[115,116]$. Chou et al. [117] developed a tunable photocatalyst based on single- and few- layered $\mathrm{MoS}_{2}$ nanosheets (Fig. 8(a) and (b)) and their piezopotential could be triggered by ambient mechanical deformation and light irradiation. The band gap of single layered $\mathrm{MoS}_{2}$ is $1.8 \mathrm{eV}$, which can generate electrons and holes under the excitation of visible light. The piezoelectric properties of odd layered $\mathrm{MoS}_{2}$ could be utilized to construct a built-in piezoelectric field under a mechanical force, promoting the migration of electrons and holes to opposite sides (Fig. 8(c)). $\mathrm{MoS}_{2}$ was grown on a carbon fiber (CF) substrate to demonstrate the feasibility of large-area production. In addition, the $\mathrm{Au}$ nanoparticles are deposited on $\mathrm{MoS}_{2}$ to improve photocatalytic activity and sterilization performance because of the prolonged
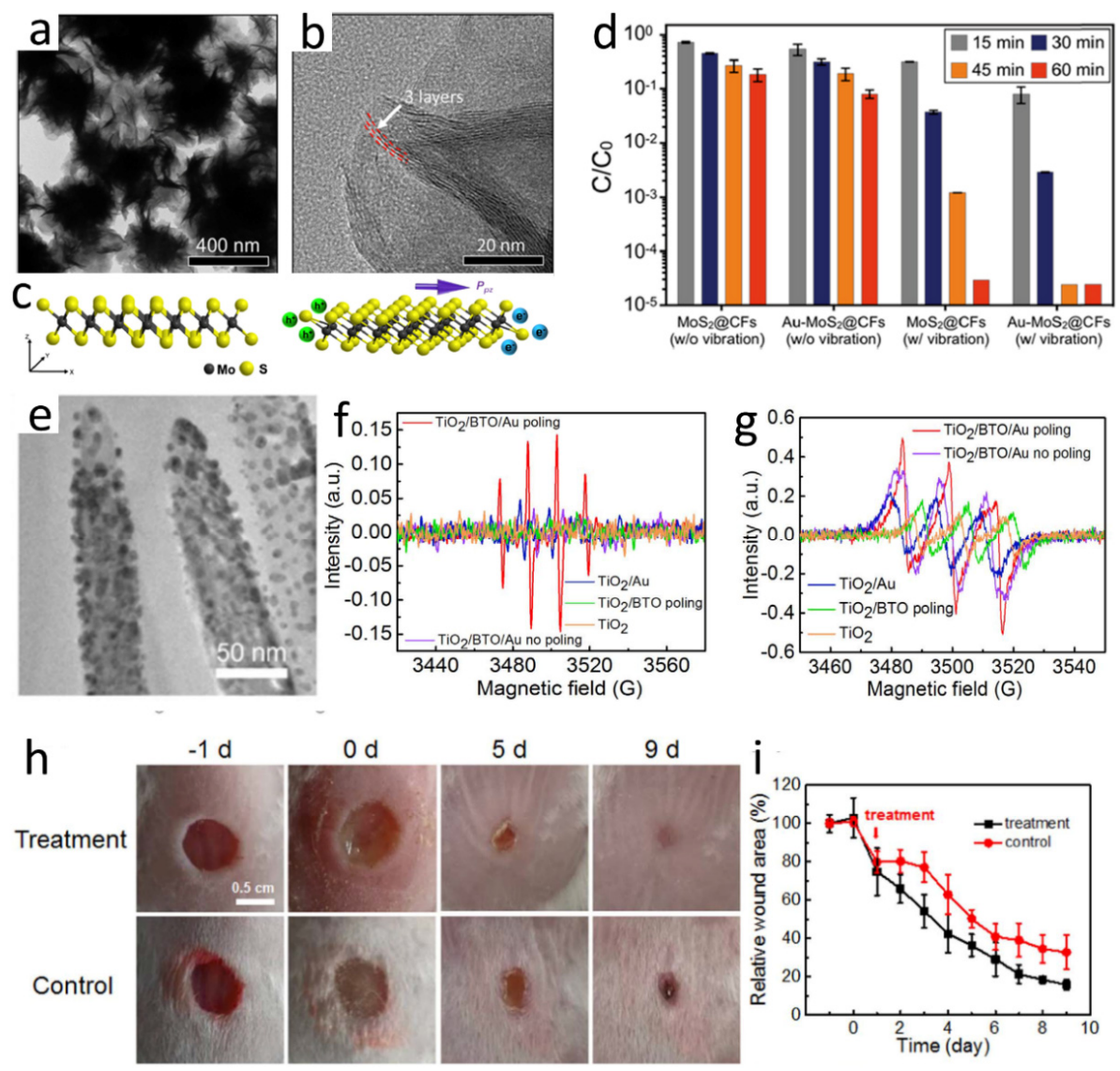

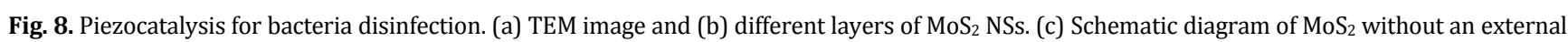
force (left) and charge transfer to compensate for the electric field generated by piezoelectric polarization at active edge sites under an external force (right). (d) Disinfection performance of $\mathrm{MoS}_{2} @ \mathrm{CFs}$ with and without deposited Au NPs [117]. Reproduced with permission [117]. Copyright 2018, Elsevier. (e) TEM image of $\mathrm{TiO}_{2} / \mathrm{BTO} / \mathrm{Au}$ nanorods. Measurement of ROS generation and PEC performance, and the deduced mechanism. ESR spectra of (f) DMPO- $\bullet \mathrm{OH}$ with DMPO as the spin-trapping adduct of $\bullet \mathrm{OH}$ and (g) TEMPONE with TEMP as the spin-trapping adduct of ${ }^{1} \mathrm{O}_{2}$. (h) Representative photographs of wound closure during the nine days of the in vivo treatment. S. aureus infected wounds were exposed to simulated sunlight for 30 min. (i) Relative wound closure (relative area versus initial area) [118]. Reproduced with permission [118]. Copyright 2018, Elsevier. 
lifetime of separate electron-hole pairs. When mechanical vibration and near-infrared (NIR)-light irradiation were simultaneously applied, 99.999\% of Escherichia coli (E. Coli) was killed within $15 \mathrm{~min}$, which was significantly shorter than the case without mechanical vibration $(\approx 60 \mathrm{~min}$ ) (Fig. 8(d)). Moreover, after treating the substrate for $45 \mathrm{~min}$ with Au-MoS $\mathrm{S}_{2} @ \mathrm{CFs}$ under NIR-light irradiation and mechanical vibration, there was no live $E$. Coli detected or recovered. The inactivation of bacteria was mainly caused by hydroxyl radicals and superoxide anions.

Our group used piezopotential augmented photocatalysis for antibacterial photocatalytic therapy [118]. For open wounds, frequent application of an external force would not only cause pain to the patient, but also is not conducive to wound recovery. Ferroelectric materials have advantages over piezoelectric semiconductors because they can generate a polarization potential without an external force. Therefore, we selected the $\mathrm{BaTiO}_{3}$ nanolayer as a ferroelectric intercalation and constructed a built-in piezoelectric field between $\mathrm{TiO}_{2}$ nanorod and gold nanoparticles (Au NPs) to fabricate a $\mathrm{TiO}_{2} / \mathrm{BTO} / \mathrm{Au}$ coaxial nanorod array (Fig. 8(e)). $\mathrm{TiO}_{2}$ could be excited only by high-energy UV light, which has limited tissue penetration, and could cause damage to normal tissues at high irradiation doses [119]. The $\mathrm{Au}$ NPs with localized surface plasmon resonance (LSPR) were combined with $\mathrm{TiO}_{2}$ to extend the light absorbance from UV to the visible region. The $\mathrm{TiO}_{2} / \mathrm{BTO} / \mathrm{Au}$ generated more $\mathrm{ROS}\left(\mathrm{O}_{2} \bullet^{-}\right.$and $\left.\bullet \mathrm{OH}\right)$ than $\mathrm{TiO}_{2} / \mathrm{Au}$ in the UV/visible light region (Fig. 8(f) and (g)). Moreover, ROS production was further improved after positive poling because the enhanced polarization electric field improved the separation efficiency of photogenerated carriers. The antibacterial efficiency of $\mathrm{TiO}_{2} / \mathrm{BTO} / \mathrm{Au}$ poling toward gram-negative bacterium $E$. coli and gram-positive bacterium $S$. Aureus could reach up to $99.9 \%$ under simulated sunlight. In an in vivo experiment, it could promote wound healing and regeneration in mice with $S$. aureus infected dermal wounds (Figs. 8(h) and (i)). This photoactivated antibacterial application may open a promising avenue for sterilization in public health care.

\subsection{Water splitting for $\mathrm{H}_{2}$ generation}

$\mathrm{H}_{2}$ is a chemical fuel with an energy density $\left(140 \mathrm{MJ} \mathrm{kg}^{-1}\right)$ on a weight basis that is significantly higher than those of most hydrocarbon fuels, such as currently used gasoline and diesel (40-50 MJ kg-1) [120,121]. Furthermore, $\mathrm{H}_{2}$ only produces water after burning in air, without any toxic by-products [122]. At present, industrial methods for preparing $\mathrm{H}_{2}$ include the following two pathways. (1) Electrolysis of water to produce $\mathrm{H}_{2}$. This process is non-polluting, and the prepared $\mathrm{H}_{2}$ has a high purity, but it consumes a large amount of electricity; (2) $\mathrm{H}_{2}$ production from fossil fuels. This is a traditional $\mathrm{H}_{2}$ production method that can be used for large-scale production, but it is inseparable from the dependence on fossil fuels and pollutes the environment $[123,124]$.

The photolysis of water to produce $\mathrm{H}_{2}$ began in 1972. Fujishima et al. [125] first reported the phenomenon of photocatalytic decomposition of water by a single crystal $\mathrm{TiO}_{2}$ electrode to generate $\mathrm{H}_{2}$, thus revealing the possibility of decomposing water to produce $\mathrm{H}_{2}$ by using solar energy. Photolysis of water can be achieved through two main methods: photocatalysis and the PEC process [7,126-128]. In the former, photocatalysts are dispersed in an aqueous solution, where they generate $\mathrm{H}_{2}$ and $\mathrm{O}_{2}$ under light irradiation; in the latter, photocatalysts are used as photoanodes to form a PEC cell, and although the process is similar to conventional electrolysis of water, the energy consumption is much lower. The generation of $\mathrm{H}_{2}$ and $\mathrm{O}_{2}$ by PEC water splitting is summarized in reactions (1)-(4):

Photoanode:

$$
\begin{gathered}
\text { Photocatalysts }+2 h v \rightarrow 2 \mathrm{e}^{-}+2 \mathrm{~h}^{+} \\
\mathrm{H}_{2} \mathrm{O}+2 \mathrm{~h}^{+} \rightarrow 2 \mathrm{H}^{++1 / 2} \mathrm{O}_{2}
\end{gathered}
$$

Pt electrode:

$$
2 \mathrm{H}^{+}+2 \mathrm{e}^{-} \rightarrow \mathrm{H}_{2}
$$

Overall reaction:

$$
\mathrm{H}_{2} \mathrm{O} \rightarrow \mathrm{H}_{2}+1 / 2 \mathrm{O}_{2}
$$

The $\mathrm{H}_{2}$ generated by water splitting in a photocatalyst or PEC process is a desirable clean energy in the future, which has the potential to replace traditional non-renewable fossil fuels [129-131]. Singh et al. [132] fabricated a flexible and scalable photoanode for PEC water splitting using a ferroelectric-semiconducting PVDF-NaNbO ${ }_{3}$ film. As shown in Fig. 9(a), under positive poling, a polarization electric field with the same direction was presented in both PVDF and $\mathrm{NaNbO}_{3}$. The polarized electric field in $\mathrm{NaNbO}_{3}$ was partially compensated for by the polarization in PVDF. Thus, a net positive charge was formed at the interface of $\mathrm{NaNbO}_{3}$ and PVDF, which led to a reduction in the upward band bending. However, the presence of negative ferroelectric charges at the surface of PVDF was advantageous for the transfer of the photogenerated holes to the electrolyte, which was conducive to improving the separation of photogenerated carriers and thus resulted in an enhanced photocurrent. In contrast, negative poling switched the polarization direction in $\mathrm{PVDF}$ and $\mathrm{NaNbO}_{3}$, and a net negative charge was presented at the $\mathrm{PVDF} / \mathrm{NaNbO}_{3}$ interface. It would increase the upward band bending. However, the positive charge on the surface of PVDF hindered the transfer of holes to the electrolyte. As a result, the photocurrent of the photoanode after positive poling exhibited a high photocurrent $(\sim 1.37 \mathrm{~mA}$ $\mathrm{cm}^{-2}$, Fig. 9(b)), which was 1.9 times that of a photoanode without poling, and 2.2 times that of a photoanode with negative poling. Moreover, the photocurrent was further increased by $\sim 26 \%$ under ultrasonic vibrations. These flexible piezoelectric/ferroelectric-photoelectrodes promote the construction of high-performance PEC water splitting systems.

\subsection{Organic synthesis}

Traditional organic synthesis steps are cumbersome, and the strong oxidants used are often toxic and corrosive $[133,134]$. Photoinduced organic synthesis has received increasing attention because of its consistency with the concept of green and sustainable chemistry [135-137]. Under light irradiation, a semiconductor photocatalyst can form photoinduced carries and further react to generate free radicals with strong oxidizing or reducing properties, which could catalyze 

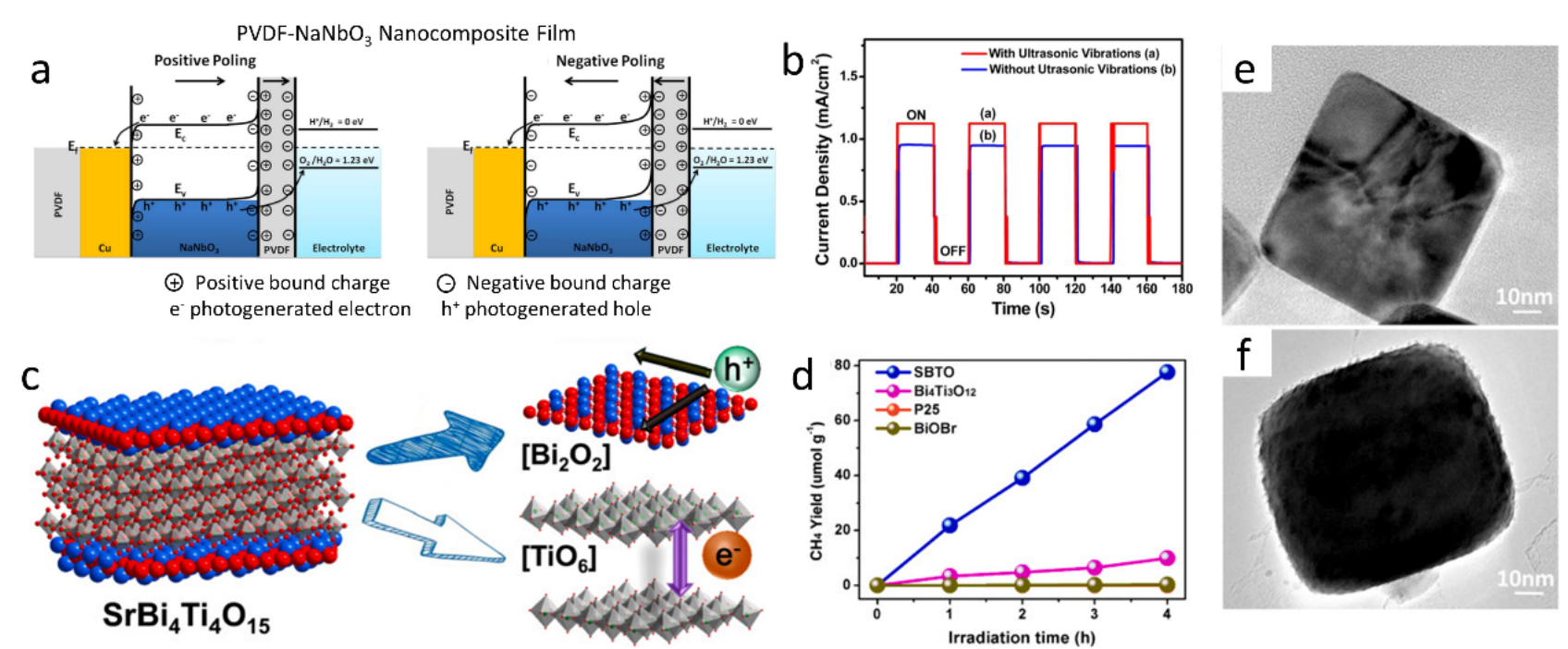

Fig. 9. Piezocatalysis for water splitting and organic synthesis. (a) Schematic representation of the band alignment between PVDF-NaNbO ${ }_{3}$ and an

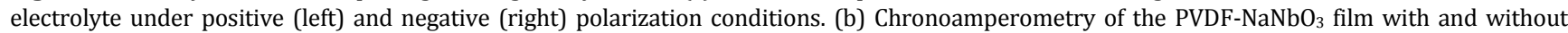
ultrasonic vibrations [132]. Reproduced with permission [132]. Copyright 2017, Elsevier. (c) Schematic diagram showing the separation and migration of photogenerated electrons and holes along different directions in the unit. (d) $\mathrm{CH}_{4}$ yield curves of $\mathrm{SrBi}_{4} \mathrm{Ti}_{4} \mathrm{O}_{15}, \mathrm{Bi}_{4} \mathrm{Ti}_{3} \mathrm{O}_{12}, \mathrm{P}_{25}$ and $\mathrm{BiOBr}_{1} \mathrm{~B}_{4}$ ]. Reproduced with permission [144]. Copyright 2019, Elsevier. TEM image of (e) $\mathrm{BaTiO}_{3}$ nanocubes and (f) BaTiO ${ }_{3} @ P A N I$ hybrid nanocubes [147]. Reproduced with permission [147]. Copyright 2017, Elsevier.

many organic synthesis reactions, including $\mathrm{CO}_{2}$ reduction, organic transformation, and free radical polymerization [138-140]. Therefore, photoinduced organic synthesis has the advantages of requiring mild reaction conditions and non-challenging photocatalyst recycling. In addition, because photoinduced organic synthesis can shorten the reaction reaction, it can effectively reduce the occurrence of side reactions and improve the purity of the target product. However, it is still challenging owing to the low efficiency of the photocatalyst [141]. The introduction of a built-in electric field in photocatalysts can significantly promote the separation of photogenerated carriers, which can be used to further improve the efficiency of organic synthesis.

Photocatalytic $\mathrm{CO}_{2}$ reduction is a strategy of killing two birds with one stone, because it can simultaneously reduce the content of greenhouse gas $\mathrm{CO}_{2}$ and form energy-bearing products $[142,143] . \mathrm{CO}_{2}$ photoreduction process involves a proton-assisted multi-electron process that yields diverse products. From the viewpoint of thermodynamics, $\mathrm{CO}_{2}$ is reduced progressively by obtaining multiple electrons and hydrogen radicals to produce gaseous and liquid hydrocarbons in the order $\mathrm{HCOOH}$ (liquid), $\mathrm{CO}$ (gas), $\mathrm{HCHO}$ (liquid), $\mathrm{CH}_{3} \mathrm{OH}$ (liquid), and $\mathrm{CH}_{4}$ (gas), as shown in Eqs. (5)-(9) [14]:

$$
\begin{aligned}
& \mathrm{CO}_{2}+2 \mathrm{H}^{+}+2 \mathrm{e}^{-} \rightarrow \mathrm{HCOOH} \\
& \left(E_{\text {redox }}=-0.61 \mathrm{~V} v s\right. \text {. NHE at pH 7) } \\
& \mathrm{CO}_{2}+2 \mathrm{H}^{+}+2 \mathrm{e}^{-} \rightarrow \mathrm{CO}+\mathrm{H}_{2} \mathrm{O} \\
& \left(E_{\text {redox }}=-0.53 \mathrm{~V} v s\right. \text {. NHE at pH 7) } \\
& \mathrm{CO}_{2}+4 \mathrm{H}^{+}+4 \mathrm{e}^{-} \rightarrow \mathrm{HCHO}+\mathrm{H}_{2} \mathrm{O} \\
& \left(E_{\text {redox }}=-0.48 \mathrm{~V} v s\right. \text {. NHE at pH 7) } \\
& \mathrm{CO}_{2}+6 \mathrm{H}^{+}+6 \mathrm{e}^{-} \rightarrow \mathrm{CH}_{3} \mathrm{OH}+\mathrm{H}_{2} \mathrm{O} \\
& \left(E_{\text {redox }}=-0.38 \mathrm{~V} v\right. \text { s. NHE at pH 7) } \\
& \mathrm{CO}_{2}+8 \mathrm{H}^{+}+8 \mathrm{e}^{-} \rightarrow \mathrm{CH}_{4}+2 \mathrm{H}_{2} \mathrm{O} \\
& \left(E_{\text {redox }}=-0.24 \mathrm{~V} v s\right. \text {. NHE at pH 7) }
\end{aligned}
$$

Tu et al. [144] employed a layered ferroelectric perovskite $\mathrm{SrBi}_{4} \mathrm{Ti}_{4} \mathrm{O}_{15}$ nanosheet as a photocatalyst for efficient $\mathrm{CO}_{2}$ reduction (Fig. 9(c)). The absorption edge of $\mathrm{SrBi}_{4} \mathrm{Ti}_{4} \mathrm{O}_{15}$ was at $\sim 420 \mathrm{~nm}$, similar to the typical bismuth-based semiconductors $\mathrm{BiOBr}$ and $\mathrm{Bi}_{4} \mathrm{Ti}_{3} \mathrm{O}_{12}$, which have a band gap of $3.0 \mathrm{eV}$. In addition, ferroelectric $\mathrm{SrBi}_{4} \mathrm{Ti}_{4} \mathrm{O}_{15}$ could form a strong polarization electric field along the [100] direction, resulting in efficient separation and migration of photoinduced carriers. The ferroelectric polarization of $\mathrm{SrBi}_{4} \mathrm{Ti}_{4} \mathrm{O}_{15}$ was adjusted by a post-annealing treatment, and $\mathrm{SrBi}_{4} \mathrm{Ti}_{4} \mathrm{O}_{15}$ nanosheets annealed at $350{ }^{\circ} \mathrm{C}$ exhibited the strongest ferroelectricity and thus displayed the highest separation efficiency of photoinduced electrons and holes. The annealed $\mathrm{SrBi}_{4} \mathrm{Ti}_{4} \mathrm{O}_{15}$ could effectively reduce $\mathrm{CO}_{2}$ to generate $\mathrm{CH}_{4}$ and $\mathrm{CO}$ without co-catalysts and sacrificial agents. Furthermore, the evolution rate of the primary product, $\mathrm{CH}_{4}$, could reach as high as $19.8 \mu \mathrm{mol} \mathrm{h}^{-1} \mathrm{~g}^{-1}$ in the gas-solid reaction system (Fig. 9(d)). Furthermore, the apparent quantum yield of $\mathrm{SrBi}_{4} \mathrm{Ti}_{4} \mathrm{O}_{15}$ was $1.33 \%$ at $365 \mathrm{~nm}$, higher than the values reported for most semiconductor photocatalysts.

Conventional electrochemical polymerization is carried out on a macroscopic electrode by applying a direct current power $[145,146]$. Therefore, it is difficult to carry out electrochemical polymerization on the surface of the individual nanoparticles because it is difficult to connect all of the nanocrystals to a power source, especially in a liquid system. Zhao et al. [147] utilized spontaneous polarized charges on the surface of ferroelectric $\mathrm{BaTiO}_{3}$ for in situ synthesis of polyaniline on the surface of $\mathrm{BaTiO}_{3}$ nanocubes (Fig. 9(e) and (f)). Furthermore, an ultrasonic wave was introduced to renew the piezoelectric charges of $\mathrm{BaTiO}_{3}$ nanocubes and further enhance the polymerization reaction. The micro-scale electrochemical cell induced by the piezoelectric potential significantly increased the reaction rate, 
providing a new path for electrochemical polymerization.

\section{Conclusions and prospect}

In summary, the ability of piezoelectric materials to create a built-in electrical field, including a piezopotential driven by mechanical deformation and spontaneous ferroelectric polarization, has inspired the development of promising catalysts. Under mechanical deformation or spontaneous polarization, the positive and negative charge centers of piezoelectric materials separate, thereby creating a polarization electric field. Driven by this electric field, photo-generated electrons and holes move in opposite directions and are effectively separated. As a result, more charge carriers reach the surface of the catalysts for redox catalytic reactions such as the degradation of pollutants, bacterial disinfection, water splitting for $\mathrm{H}_{2}$ evolution, and organic synthesis. Piezoelectric semiconductors exhibit a polarization electric field only under mechanical deformation. Compared to piezoelectric semiconductors, ferroelectric materials can form a spontaneous polarization electric field in the absence of an additional mechanical force. In addition, the dipole can be further polarized by an external electric field, which facilitates the construction of a built-in electric field in situations where applying external forces is inconvenient, such as during an open wound healing process. However, the static polarized electric field will be weakened or even totally screened by carriers from the photoinduced material or electrolyte if there is no change in the external electric field and mechanical force. Therefore, although the built-in electric field can significantly improve the separation of carriers, there is room for further improving the efficiency of piezocatalysts.

To make better use of piezoelectricity and ferroelectricity to improve the separation efficiency of photogenerated electrons and holes, we should have a deeper understanding of the structure and properties of the selected polarized materials, thereby determining the direction of the applied external force or polarized electric field, and the polarization enhancement by fine-tuning the crystal structure. In addition, more attention should be paid to the mechanisms that facilitate the rational combination of piezoelectric materials and semiconductor photocatalysts to achieve higher photocatalytic effects. Whether the polarized carriers participate in the redox catalytic reaction is still controversial. Some researchers believe that photogenerated electrons/holes play a key role in redox reactions, and the polarization potential of piezoelectric materials only promotes the separation of photogenerated carriers [98]. However, numerous studies have shown that regulation of redox reactions can be achieved simply with a piezoelectric potential in the dark and does not require the participation of photogenerated carriers [45,148-150]. Moreover, the application of period deformation plays an important role in both the piezoelectric and ferroelectric enhanced catalytic process. For piezoelectric semiconductors, mechanical deformation caused by an external force is the basis for generating a piezoelectric potential. For ferroelectric materials, the periodic deformation can renew the polarization potential, preventing the saturation of the static built-in field [31]. However, the methods common- ly used to deform piezoelectric semiconductors need to be deliberately designed to provide a force, which limits their practical application. Furthermore, mechanical energy in nature (wind energy, water flow, and tidal energy) is relatively mild and its frequency is low; thus the generated piezoelectric potential is also insufficient. Therefore, the rational design of the catalyst structure, such as using a spiral [52] or foam [76] structure to better utilize the mechanical forces in nature, also has great significance for improving the photocatalytic effect. A deeper understanding and novel design of high-performance photocatalysts along these perspectives might make piezocatalysts a powerful tool for solving the current environmental and energy crises in the future.

\section{References}

[1] W. Wang, M. O. Tade, Z. P. Shao, Chem. Soc. Rev., 2015, 44, 5371-5408.

[2] N. Y. Cheng, J. Q. Tian, Q. Liu, C. J. Ge, A. H. Qusti, A. M. Asiri, A. O. Al-Youbi, X. P. Sun, ACS Appl. Mater. Interfaces, 2013, 5, 6815-6819.

[3] Y. AlSalka, L. I. Granone, W. Ramadan, A. Hakki, R. Dillert, D. W. Bahnemann, Appl. Catal. B, 2019, 244, 1065-1095.

[4] T. T. Yao, X. R. An, H. X. Han, J. Q. Chen, C. Li, Adv. Energy Mater, 2018, 8, 1800210.

[5] S. S. Zhu, D. W. Wang, Adv. Energy Mater., 2017, 7, 1700841.

[6] S. Chandrasekaran, T. Nann, N. H. Voelcker, Nano Energy, 2015, 17, 308-322.

[7] X. Yu, X. Han, Z. H. Zhao, J. Zhang, W. B. Guo, C. F. Pan, A. X. Li, H. Liu, Z. L. Wang, Nano Energy, 2015, 11, 19-27.

[8] S. Rtimi, S. Giannakis, M. Bensimon, C. Pulgarin, R. Sanjines, J. Kiwi, Appl. Catal. B, 2016, 191, 42-52.

[9] A. Kudo, Y. Miseki, Chem. Soc. Rev., 2009, 38, 253-278.

[10] X. C. Wang, K. Maeda, A. Thomas, K. Takanabe, G. Xin, J. M. Carlsson, K. Domen, M. Antonietti, Nat. Mater., 2009, 8, 76-80.

[11] H. L. Wang, L. S. Zhang, Z. G. Chen, J. Q. Hu, S. J. Li, Z. H. Wang, J. S. Liu, X. C. Wang, Chem. Soc. Rev., 2014, 43, 5234-5244.

[12] R. Marschall, Adv. Funct. Mater., 2014, 24, 2421-2440.

[13] X. C. Ma, X. Wu, H. D. Wang, Y. C. Wang, J. Mater. Chem. A, 2018, 6, 2295-2301.

[14] W. J. Ong, L. L. Tan, Y. H. Ng, S. T. Yong, S. P. Chai, Chem. Rev., 2016, 116, 7159-7329.

[15] J. W. Fu, J. G. Yu, C. J. Jiang, B. Cheng, Adv. Energy Mater., 2018, 8, 1701503.

[16] F. F. Abdi, L. H. Han, A. H. M. Smets, M. Zeman, B. Dam, R. van de Krol, Nat. Commun., 2013, 4, 2195.

[17] Y. Hou, F. Zuo, A. Dagg, P. Y. Feng, Nano Lett., 2012, 12, 6464-6473.

[18] T. J. Yan, J. Tian, W. F. Guan, Z. Qiao, W. J. Li, J. M. You, B. B. Huang, Appl. Catal. B, 2017, 202, 84-94.

[19] M. B. Tahir, M. Sagir, K. Shahzad, J. Hazard. Mater., 2019, 363, 205-213.

[20] X. B. Meng, J. L. Sheng, H. L. Tang, X. J. Sun, H. Dong, F. M. Zhang, Appl. Catal. B, 2019, 244, 340-346.

[21] X. Yu, N. Ren, J. C. Qiu, D. H. Sun, L. L. Li, H. Liu, Sol. Energy Mater. Sol. Cells, 2018, 183, 41-47.

[22] X. Yu, Z. H. Zhao, D. H. Sun, N. Ren, J. H. Yu, R. Q. Yang, H. Liu, Appl. Catal. B, 2018, 227, 470-476.

[23] X. Yu, Z. H. Zhao, N. Ren, J. Liu, D. H. Sun, L. H. Ding, H. Liu, ACS Sustainable Chem. Eng., 2018, 6, 11775-11782.

[24] S. W. Cao, J. X. Low, J. G. Yu, M. Jaroniec, Adv. Mater., 2015, 27, 


\section{Graphical Abstract}

\section{Chin. J. Catal., 2020, 41: 534-549 doi: S1872-2067(19)63431-5}

Piezopotential augmented photo- and photoelectro-catalysis with a built-in electric field

Zhirong Liu, Xin Yu, Linlin Li*

Beijing Institute of Nanoenergy and Nanosystems, CAS;

University of Jinan;

University of Chinese Academy of Sciences;

Guangxi University

The built-in electric field generated by piezoelectric and ferroelectric materials can efficiently separate photoinduced carriers, thereby promoting redox catalytic reactions, such as the degradation of pollutants, bacterial disinfection, water splitting, and organic synthesis.

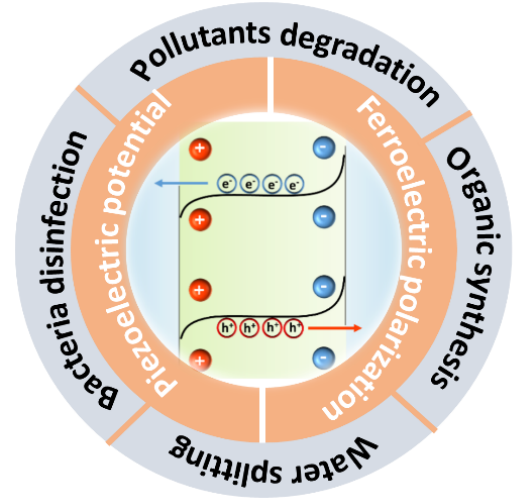

\section{0-2176.}

[25] . Kurnaravel, S. Mathew, J. Bartlett, S. C. Pillai, Appl. Catal. B, 2019, 244, 1021-1064.

[26] S. Zhang, Y. Liu, P. C. Gu, R. Ma, T. Wen, G. X. Zhao, L. Li, Y. J. Ai, C. Hu, X. K. Wang, Appl. Catal. B, 2019, 248, 1-10.

[27] J. X. Low, B. Z. Dai, T. Tong, C. J. Jiang, J. G. Yu, Adv. Mater., 2019, 31, 1802981.

[28] X. Yu, Z. H. Zhao, D. H. Sun, N. Ren, L. H. Ding, R. Q. Yang, Y. C. Ji, L. L. Li, H. Liu, Chem. Commun., 2018, 54, 6056-6059.

[29] G. S. Li, Z. C. Lian, W. C. Wang, D. Q. Zhang, H. X. Li, Nano Energy, 2016, 19, 446-454.

[30] J. Li, X. Gao, Z. Z. Li, D. H. Wang, L. Zhu, C. Yin, Y. Wang, X. B. Li, Z. F. Liu, J. Zhang, C. H. Tung, L. Z. Wu, Adv. Funct. Mater., 2019, 29, 1808079.

[31] H. D. Li, Y. H. Sang, S. J. Chang, X. Huang, Y. Zhang, R. S. Yang, H. D. Jiang, H. Liu, Z. L. Wang, Nano Lett., 2015, 15, 2372-2379.

[32] X. N. Li, Z. Ju, F. Li, Y. Huang, Y. M. Xie, Z. P. Fu, R. J. Knize, Y. L. Lu, J. Mater. Chem. A, 2014, 2, 13366-13372.

[33] H. X. Fu, R. E. Cohen, Nature, 2000, 403, 281-283.

[34] D. Kan, L. Palova, V. Anbusathaiah, C. J. Cheng, S. Fujino, V. Nagarajan, K. M. Rabe, I. Takeuchi, Adv. Funct. Mater., 2010, 20, 1108-1115.

[35] Z. L. Wang, Nano Today, 2010, 5, 540-552.

[36] Y. Zhang, Y. Liu, Z. L. Wang, Adv. Mater., 2011, 23, 3004-3013.

[37] C. Falconi, Nano Energy, 2019, 59, 730-744.

[38] Y. Yang, W. X. Guo, Y. Zhang, Y. Ding, X. Wang, Z. L. Wang, Nano Lett., 2011, 11, 4812-4817.

[39] Z. L. Wang, Adv. Mater., 2012, 24, 4632-4646.

[40] C. F. Pan, M. X. Chen, R. M. Yu, Q. Yang, Y. F. Hu, Y. Zhang, Z. L. Wang, Adv. Mater, 2016, 28, 1535-1552.

[41] Q. Yang, X. Guo, W. H. Wang, Y. Zhang, S. Xu, D. H. Lien, Z. L. Wang, ACS Nano, 2010, 4, 6285-6291.

[42] Y. Zhao, X. Huang, F. Gao, L. Zhang, Q. Tian, Z.-B. Fang, P. Liu, Nanoscale, 2019, 11, 9085-9090.

[43] F. Chen, H. Huang, L. Guo, Y. Zhang, T. Ma, Angew. Chem. Int. Ed., 2019, DOI: 10.1002/anie.201901361.

[44] W. Z. Wu, L. Wang, Y. L. Li, F. Zhang, L. Lin, S. M. Niu, D. Chenet, X. Zhang, Y. F. Hao, T. F. Heinz, J. Hone, Z. L. Wang, Nature, 2014, 514, 470-474.

[45] M. H. Wu, J. T. Lee, Y. J. Chung, M. Srinivaas, J. M. Wu, Nano Energy, 2017, 40, 369-375.
[46] Y. F. Cui, H. H. Sun, J. Briscoe, R. Wilson, N. Tarakina, S. Dunn, Y. P. $\mathrm{Pu}$, Nanotechnology, 2019, 30, 255702.

[47] H. W. Huang, S. C. Tu, C. Zeng, T. R. Zhang, A. H. Reshak, Y. H. Zhang, Angew. Chem. Int. Ed., 2017, 56, 11860-11864.

[48] Y. K. Zhu, P. K. Jiang, Z. C. Zhang, X. Y. Huang, Chin. Chem. Lett., 2017, 28, 2027-2035.

[49] D. F. Pang, X. T. Liu, X. He, C. Chen, J. Zheng, Z. G. Yi, J. Am. Ceram. Soc., 2019, 102, 3448-3456.

[50] Z. Y. Gao, J. Zhou, Y. D. Gu, P. Fei, Y. Hao, G. Bao, Z. L. Wang, J. Appl. Phys., 2009, 105, 113707/1-113707/6.

[51] M. P. Lu, J. Song, M. Y. Lu, M. T. Chen, Y. Gao, L. J. Chen, Z. L. Wang, Nano Lett., 2009, 9, 1223-1227.

[52] B. Y. Dai, Y. R. Yu, Y. K. Chen, H. M. Huang, C. H. Lu, J. H. Kou, Y. J. Zhao, Z. Z. Xu, Adv. Funct. Mater., 2019, 29, 1807934.

[53] X. Cheng, Y. J. Zhang, Y. P. Bi, Nano Energy, 2019, 57, 542-548.

[54] Z. R. Liu, L. W. Wang, X. Yu, J. Zhang, R. Q. Yang, X. D. Zhang, Y. C. Ji, M. Q. Wu, L. Deng, L. L. Li, Z. L. Wang, Adv. Funct. Mater., 2019, 1807279.

[55] M. Trieloff, E. K. Jessberger, I. Herrwerth, J. Hopp, C. Fieni, M. Ghelis, M. Bourot-Denise, P. Pellas, Nature, 2003, 422, 502-506.

[56] S. S. Singh, P. Pal, A. K. Pandey, J. Appl. Phys., 2015, 118, 204303.

[57] L. F. Wang, M. R. Cho, Y. J. Shin, J. R. Kim, S. Das, J. G. Yoon, J. S. Chung, T. W. Noh, Nano Lett., 2016, 16, 3911-3918.

[58] K. Maeda, ACS Appl. Mater. Interfaces, 2014, 6, 2167-2173.

[59] M. Dahl, Y. D. Liu, Y. D. Yin, Chem. Rev., 2014, 114, 9853-9889.

[60] X. Yu, J. Zhang, Z. H. Zhao, W. B. Guo, J. C. Qiu, X. N. Mou, A. X. Li, J. P. Claverie, H. Liu, Nano Energy, 2015, 16, 207-217.

[61] T. Xia, W. Zhang, J. Murowchick, G. Liu, X. B. Chen, Nano Lett., 2013, 13, 5289-5296.

[62] Z. Zhang, J. T. Yates, Chem. Rev., 2012, 112, 5520-5551.

[63] K. Woan, G. Pyrgiotakis, W. Sigmund, Adv. Mater., 2009, 21, 2233-2239.

[64] L. Li, P. A. Salvador, G. S. Rohrer, Nanoscale, 2014, 6, 24-42.

[65] A. Kubacka, M. Fernandez-Garcia, G. Colon, Chem. Rev., 2012, 112, 1555-1614.

[66] H. Petek, J. Zhao, Chem. Rev., 2010, 110, 7082-7099.

[67] Z. Liang, C. F. Yan, S. Rtimi, J. Bandara, Appl. Catal. B, 2019, 241, 256-269.

[68] J. Shi, M. B. Starr, H. Xiang, Y. Hara, M. A. Anderson, J. H. Seo, Z. Q. Ma, X. D. Wang, Nano Lett., 2011, 11, 5587-5593.

[69] H. X. Li, Y. H. Yu, M. B. Starr, Z. D. Li, X. D. Wang, J. Phys. Chem. Lett, 
2015, 6, 3410-3416.

[70] X. Y. Xue, W. L. Zang, P. Deng, Q. Wang, L. L. Xing, Y. Zhang, Z. L. Wang, Nano Energy, 2015, 13, 414-422.

[71] J. X. Feng, Y. Fu, X. S. Liu, S. H. Tian, S. Y. Lan, Y. Xiong, ACS Sustain. Chem. Eng., 2018, 6, 6032-6041.

[72] J. Wu, N. Qin, D. H. Bao, Nano Energy, 2018, 45, 44-51.

[73] E. B. Flint, K. S. Suslick, Science, 1991, 253, 1397-1399.

[74] X. T. Pan, Q. Y. Wu, H. Y. Wang, S. Liu, B. L. Xu, H. Y. Liu, L. X. Bai, H. Wang, X. H. Shi, Adv. Mater., 2018, 30, e1800180.

[75] L. F. Wang, S. H. Liu, Z. Wang, Y. L. Zhou, Y. Qin, Z. L. Wang, ACS Nano, 2016, 10, 2636-2643.

[76] X. Y. Chen, L. F. Liu, Y. W. Feng, L. F. Wang, Z. F. Bian, H. X. Li, Z. L. Wang, Mater. Today, 2017, 20, 501-506.

[77] Y. W. Feng, H. Li, L. L. Ling, S. Yan, D. L. Pan, H. Ge, H. X. Li, Z. F. Bian, Environ. Sci. Technol., 2018, 52, 7842-7848.

[78] B. Y. Dai, C. H. Lu, J. H. Kou, Z. Z. Xu, F. L. Wang, J. Alloys Compd., 2017, 696, 988-995.

[79] W. S. Tong, Y. H. Zhang, H. W. Huang, K. Xiao, S. X. Yu, Y. Zhou, L. P. Liu, H. T. Li, L. Liu, T. Huang, M. Li, Q. Zhang, R. F. Du, Q. An, Nano Energy, 2018, 53, 513-523.

[80] C. F. Tan, W. L. Ong, G. W. Ho, ACS Nano, 2015, 9, 7661-7670.

[81] X. Han, M. X. Chen, C. F. Pan, Z. L. Wang, J. Mater. Chem. C, 2016, 4, 11341-11354.

[82] W. Z. Wu, Z. L. Wang, Nat. Rev. Mater., 2016, 1, 16031.

[83] Y. H. Yu, X. D. Wang, Adv. Mater., 2018, 30, 1800154.

[84] F. Mushtaq, X. Z. Chen, M. Hoop, H. Torlakcik, E. Pellicer, J. Sort, C. Gattinoni, B. J. Nelson, S. Pané, iScience, 2018, 4, 236-246.

[85] M. Wang, B. Wang, F. Huang, Z. Lin, Angew. Chem. Int. Ed., 2019, 58, 7526-7536.

[86] J. Wu, Q. Xu, E. Z. Lin, B. W. Yuan, N. Qin, S. K. Thatikonda, D. H. Bao, ACS Appl. Mater. Interfaces, 2018, 10, 17842-17849.

[87] P. H. Wen, F. Y. Yao, D. W. Hu, J. J. Guo, Y. Z. Lan, C. C. Wang, X. G. Kong, Q. Feng, Mater. Design, 2018, 158, 5-18.

[88] H. J. Liu, C. W. Du, M. Li, S. S. Zhang, H. K. Bai, L. Yang, S. Q. Zhang, ACS Appl. Mater. Inter., 2018, 10, 28686-28694.

[89] Z. H. Zhao, J. Tian, Y. H. Sang, A. Cabot, H. Liu, Adv. Mater., 2015, 27, 2557-2582.

[90] M. Q. Lyu, J. H. Yun, P. Chen, M. M. Hao, L. Z. Wang, Adv. Energy Mater., 2017, 7, 1602512.

[91] X. H. Gao, H. B. Wu, L. X. Zheng, Y. J. Zhong, Y. Hu, X. W. Lou, Angew. Chem. Int. Ed., 2014, 53, 5917-5921.

[92] X. J. Yuan, D. Floresyona, P. H. Aubert, T. T. Bui, S. Remita, S. Ghosh, F. Brisset, F. Goubard, H. Remita, Appl. Catal. B, 2019, 242, 284-292.

[93] S. Y. Xu, L. M. Guo, Q. J. Sun, Z. L. Wang, Adv. Funct. Mater., 2019, 29, 1808737.

[94] Y. Wu, Y. L. Wei, Q. Y. Guo, H. Xu, L. Gu, F. Y. Huang, D. Luo, Y. F. Huang, L. Q. Fan, J. H. Wu, Sol. Energy Mater. Sol. Cells, 2018, 176, 230-238.

[95] C. Y. Zou, S. Q. Liu, Z. M. Shen, Y. Zhang, N. S. Jiang, W. C. Ji, Chin. J. Catal., 2017, 38, 20-28.

[96] Y. Y. Wu, L. L. Zhang, Y. Z. Zhou, L. L. Zhang, Y. Li, Q. Q. Liu, J. Hu, J. Yang, Chin. J. Catal., 2019, 40, 691-702.

[97] Y. Z. Zhang, X. L. Huang, J. Yeom, Nano-Micro Lett., 2019, 11, 11.

[98] D. Y. Hong, W. L. Zang, X. Guo, Y. M. Fu, H. X. He, J. Sun, L. L. Xing, B. D. Liu, X. Y. Xue, ACS Appl. Mater. Interfaces, 2016, 8, 21302-21314.

[99] Y. L. Liu, J. M. Wu, Nano Energy, 2019, 56, 74-81.

[100] K. E. Jones, N. G. Patel, M. A. Levy, A. Storeygard, D. Balk, J. L. Gittleman, P. Daszak, Nature, 2008, 451, 990-993.

[101] C. Gradmann, Med. Hist., 2016, 60, 155-180.

[102] M. I. Jacob, Genet. Eng. News, 1997, 17, 6.
[103] E. Stokstad, Science, 2000, 287, 2391-2391.

[104] D. B. Jack, Mol. Med. Today, 1996, 2, 499-502.

[105] T. Matsunaga, R. Tomoda, T. Nakajima, H. Wake, Fems. Microbiol. Lett., 1985, 29, 211-214.

[106] M. Salehi, A. Eshaghi, H. Tajizadegan, J. Alloys Compd., 2019, 778, 148-155.

[107] P. A. Charpentier, C. Chen, K. Azhie, B. Grohe, M. A. Mumin, A. F. Lotus, P. Therrien, S. Mittler, Nanotechnology, 2019, 30, 085706.

[108] S. S. Lucky, K. C. Soo, Y. Zhang, Chem. Rev., 2015, 115, 1990-2042.

[109] X. J. Song, C. Liang, H. Gong, Q. Chen, C. Wang, Z. Liu, Small, 2015, 11, 3932-3941.

[110] C. Liu, D. S. Kong, P. C. Hsu, H. T. Yuan, H. W. Lee, Y. Y. Liu, H. T. Wang, S. Wang, K. Yan, D. C. Lin, P. A. Maraccini, K. M. Parker, A. B. Boehm, Y. Cui, Nat. Nanotechnol., 2016, 11, 1098-1104.

[111] Y. J. Li, Q. Q. Wang, H. X. Wang, J. Tian, H. Z. Cui, J. Colloid Interf. Sci., 2019, 537, 206-214.

[112] S. A. Han, T. H. Kim, S. K. Kim, K. H. Lee, H. J. Park, J. H. Lee, S. W. Kim, Adv. Mater., 2018, 30, 1800342.

[113] H. J. Jin, W. Y. Yoon, W. Jo, ACS Appl. Mater. Inter., 2018, 10, 1334-1339.

[114] L. J. Li, Y. Zhang, Nano Res., 2017, 10, 2527-2534.

[115] K. A. N. Duerloo, M. T. Ong, E. J. Reed, J. Phys. Chem. Lett., 2012, 3, 2871-2876.

[116] K. H. Michel, B. Verberck, Phys. Rev. B, 2011, 83, 115328.

[117] T. M. Chou, S. W. Chan, Y. J. Lin, P. K. Yang, C. C. Liu, Y. J. Lin, J. M. Wu, J. T. Lee, Z. H. Lin, Nano Energy, 2019, 57, 14-21.

[118] X. Yu, S. Wang, X. D. Zhang, A. H. Qi, X. R. Qiao, Z. R. Liu, M. Q. Wu, L. L. Li, Z. L. Wang, Nano Energy, 2018, 46, 29-38.

[119] E. A. Rozhkova, I. Ulasov, B. Lai, N. M. Dimitrijevic, M. Lesniak, T. Rajh, Nano Lett., 2009, 9, 3337-3342.

[120] R. Lachner, J. DiCampli, R. M. Jones, B. Mehmetli, P. Popovic, T. Raddings, Vdi. Bericht., 2012, 2177, 187-198.

[121] Y. O. Wang, H. Suzuki, J. J. Xie, O. Tomita, D. J. Martin, M. Higashi, D. Kong, R. Abe, J. W. Tang, Chem. Rev., 2018, 118, 5201-5241.

[122] S. C. Wang, P. Chen, J. H. Yun, Y. X. Hu, L. Z. Wang, Angew. Chem. Int. Ed., 2017, 56, 8500-8504.

[123] R. Tarkowski, Renew. Sust. Energ. Rev., 2019, 105, 86-94.

[124] J. H. Wang, W. Cui, Q. Liu, Z. C. Xing, A. M. Asiri, X. P. Sun, Adv. Mater., 2016, 28, 215-230.

[125] A. Fujishima, K. Honda, Nature, 1972, 238, 37-38.

[126] R. G. Li, Chin. J. Catal., 2017, 38, 5-12.

[127] S. W. Boettcher, T. E. Mallouk, F. E. Osterloh, J. Mater. Chem. A, 2016, 4, 2764-2765.

[128] Q. Z. Wang, T. J. Niu, L. Wang, J. W. Huang, H. D. She, Chin. J. Catal., 2018, 39, 613-618.

[129] Y. S. Jia, D. Zhao, M. R. Li, H. X. Han, C. Li, Chin. J. Catal., 2018, 39, 421-430.

[130] B. J. Ma, R. S. Zhang, K. Y. Lin, H. X. Liu, X. Y. Wang, W. Y. Liu, H. J. Zhan, Chin. J. Catal., 2018, 39, 527-533.

[131] B. Q. Wang, Y. Ding, Z. R. Deng, Z. H. Li, Chin. J. Catal., 2019, 40, 335-342.

[132] S. Singh, N. Khare, Nano Energy, 2017, 42, 173-180.

[133] G. R. Desiraju, Angew. Chem. Int. Ed., 1995, 34, 2311-2327.

[134] K. Tanaka, F. Toda, Chem. Rev., 2000, 100, 1025-1074.

[135] S. Dadashi-Silab, S. Doran, Y. Yagci, Chem. Rev., 2016, 116, 10212-10275.

[136] T. P. Yoon, M. A. Ischay, J. N. Du, Nat. Chem., 2010, 2, 527-532.

[137] A. Albini, M. Fagnoni, Green Chem., 2004, 6, 1-6.

[138] M. S. Liu, T. Y. Peng, H. N. Li, L. Zhao, Y. H. Sang, Q. W. Feng, L. Xu, Y. H. Jiang, H. Liu, J. M. Zhang, Appl. Catal. B, 2019, 249, 172-210.

[139] J. H. Guo, Y. T. Cao, R. Shi, G. I. N. Waterhouse, L. Z. Wu, C. H. Tung, 
T. R. Zhang, Angew. Chem. Int. Ed., 2019, 58, 8443-8447.

[140] W. Wang, L. Shang, G. J. Chang, C. Y. Yan, R. Shi, Y. X. Zhao, G. I. N. Waterhouse, D. J. Yang, T. R. Zhang, Adv. Mater., 2019, 31, 1808276.

[141] J. Tian, Z. H. Zhao, A. Kumar, R. I. Boughton, H. Liu, Chem. Soc. Rev., 2014, 43, 6920-6937.

[142] L. L. Tan, W. J. Ong, S. P. Chai, A. R. Mohamed, Nanoscale Res. Lett., 2013, 8, 465.

[143] W. G. Tu, Y. Zhou, Z. G. Zou, Adv. Mater., 2014, 26, 4607-4626.

[144] S. C. Tu, Y. H. Zhang, A. H. Reshak, S. Auluck, L. Q. Ye, X. P. Han, T. Y. Ma, H. W. Huang, Nano Energy, 2019, 56, 840-850.

[145] C. Peng, G. A. Snook, D. J. Fray, M. S. P. Shaffer, G. Z. Chen, Chem.
Commun., 2006, 4629-4631.

[146] S. W. Zhang, L. P. Zhao, M. Y. Zeng, J. X. Li, J. Z. Xu, X. K. Wang, Catal. Today, 2014, 224, 114-121.

[147] L. L. Zhao, Y. Zhang, F. L. Wang, S. C. Hu, X. N. Wang, B. J. Ma, H. Liu, Z. L. Wang, Y. H. Sang, Nano Energy, 2017, 39, 461-469.

[148] S. Masimukku, Y. C. Hu, Z. H. Lin, S. W. Chan, T. M. Chou, J. M. Wu, Nano Energy, 2018, 46, 338-346.

[149] Y. Su, L. Zhang, W. Z. Wang, X. M. Li, Y. L. Zhang, D. K. Shao, J. Mater. Chem. A, 2018, 6, 11909-11915.

[150] M. Y. Wang, B. Wang, F. Huang, Z. Q. Lin , Angew. Chem. Int. Ed., 2019, 131, 7606-7616.

\title{
压电势构建的内建电场增强光催化和光电催化
}

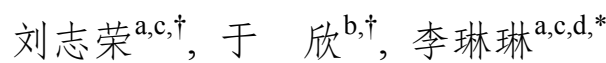 \\ ${ }^{\mathrm{a}}$ 中国科学院北京纳米能源与系统研究所, 北京 100083

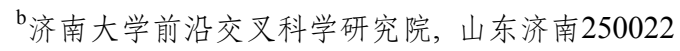 \\ $\mathrm{c}$ 中国科学院大学纳米科学与技术学院, 北京 100049 \\ $\mathrm{d}$ 广西大学物理科学与工程技术学院纳米能源研究中心, 广西南宁530004
}

\begin{abstract}
摘要: 科技的飞速发展和世界人口膨胀带来一系列迫在眉睫的环境问题和能源危机. 光催化和光电催化为缓解这些问题 提供了绿色、经济有效的途径, 已经被开发用于催化降解环境中的有机污染物、二氧化碳还原、水分解制备氢气, 把生物 质转化为清洁燃料, 以及其它反应. 通常, 具有合适能带位置和带隙的半导体可以吸收太阳光, 形成光生电子空穴对, 然后 转移到光催化剂表面, 引发氧化还原反应. 然而, 有限的太阳光利用率和光诱导电子空穴对的高复合率阻碍了它们的工业 化发展. 在过去几十年里, 研究人员已经制备了许多复合光催化剂, 用以将光吸收范围从紫外区拓宽到可见光和近红外区 域, 如 $\mathrm{g}-\mathrm{C}_{3} \mathrm{~N}_{4}, \mathrm{BiVO}_{4}, \mathrm{Fe}_{2} \mathrm{O}_{3}, \mathrm{Ag}_{3} \mathrm{PO}_{4}, \mathrm{WO}_{3}, \mathrm{CdS}, \mathrm{Sn}_{3} \mathrm{O}_{4}$ 等. 另一方面, 还通过多种改性方法促进光生电子和空穴分离, 包括 表面改性、金属/非金属掺杂和异质结设计等. 此外, 偏压有助于电子的定向传输. 因此, 光电催化可以通过光照和偏置电 压的协同作用, 进一步增强载流子的分离. 然而, 高效地分离光生载流子仍然是一个巨大的挑战.

近年来, 通过压电和铁电效应合理地构建内建电场, 以有效地增强载流子分离引起了越来越多的关注. 压电体(包括铁 电体、压电半导体等)是一类具有非中心对称晶体结构的材料. 在机械变形或外加电场作用下, 它们的正负电荷中心被分 离, 产生压电势. 压电势可以在金属-半导体接触或半导体异质结的界面处调制载流子的传输. 压电材料已被广泛用于调 节压电半导体器件的性能, 如晶体管、太阳能电池、发光二极管和自供电纳米系统. 在光催化和光电催化中, 压电半导体 和具有永久极化的铁电材料通过构建内建电场在增强载流子分离方面显示出巨大的潜力. 本综述总结了压电半导体和铁 电材料增强的压电催化(包括光电催化和光电催化)的最新进展. 首先, 文章介绍了压电和铁电材料的性质以及构建内建电 场促进载流子分离的机理. 其次, 讨论了压电势构建内建电场的具体途径, 包括超声波、机械刷/滑动、热应力、水流和铁 电永久极化. 然后, 阐明了具体的潜在应用, 例如污染物的降解、杀菌消毒、用于水分解产氢和有机合成. 最后, 文章对该 领域的挑战进行了总结, 对压电催化剂未来发展的前景进行了展望.
\end{abstract}

关键词: 光催化; 光电催化; 压电势; 内建电场; 压电光电子学效应; 活性氧

收稿日期: 2019-09-27. 接受日期: 2019-11-10. 出版日期: 2020-04-05.

*通讯联系人. 电话: (010)82854770; 传真: (010)82854800; 电子信箱: lilinlin@binn.cas.cn

†共同第一作者.

基金来源：中国科学院青年创新促进会(2015023); 国家自然科学基金(81471784, 51802115); 北京市自然科学基金(2172058); 山 东省自然科学基金(ZR2018BEM010, ZR2019YQ21); 山东省自然科学基金重大基础研究项目(ZR2018ZC0843); 济南大学科技项 目(XKY1923).

本文的电子版全文由Elsevier出版社在ScienceDirect上出版(http://www.sciencedirect.com/science/journal/18722067). 